\title{
NANOFIBROUS COMPOSITE SCAFFOLDS OF POLY (ESTER AMIDES) WITH TUNABLE PHYSICOCHEMICAL AND DEGRADATION PROPERTIES
}

by

\section{FNU Shilpaa Mukundan}

B.Tech Bioprocess Engineering, SRM University, 2012

\author{
Submitted to the Graduate Faculty of \\ School of Pharmacy in partial fulfillment \\ of the requirements for the degree of \\ Master of Science
}

University of Pittsburgh 


\section{UNIVERSITY OF PITTSBURGH \\ SCHOOL OF PHARMACY}

This thesis was presented

by

FNU Shilpaa Mukundan

It was defended on

May 07, 2015

and approved by

Dr.Shilpa Sant, Assistant Professor, Pharmaceutical Sciences

Dr.Lisa Rohan, Associate Professor, Pharmaceutical Sciences

Dr.Vinayak Sant, Associate Professor, Pharmaceutical Sciences

Thesis Director: Dr. Shilpa Sant, Assistant Professor, Pharmaceutical Sciences 
Copyright (C) by FNU Shilpaa Mukundan

2015 


\title{
NANOFIBROUS COMPOSITE SCAFFOLDS OF POLY(ESTER AMIDES) WITH TUNABLE PHYSICOCHEMICAL AND DEGRADATION PROPERTIES
}

\author{
FNU Shilpaa Mukundan, B.Tech. \\ University of Pittsburgh, 2015
}

Polymeric elastomers like Poly (1,3-diamino-2-hydroxypropane-co-polyol sebacate) (APS) have gained importance in soft tissue engineering applications due to their tunable mechanical properties and biodegradability. The fabrication of extracellular matrix (ECM)-mimetic nanofibrous scaffolds using APS is however limited due to its poor solubility in commonly used solvents, low viscosity and high temperatures required for thermal curing. In this study, we have overcome these limitations of APS by blending un-crosslinked APS pre-polymer with polycaprolactone (PCL), and have successfully fabricated ECM-mimetic nanofibrous APS scaffolds for the first time. The developed fibrous scaffolds were further characterized for their physicochemical, thermal, mechanical and degradation properties. Effects of APS:PCL weight ratios $(0: 1,1: 1,2: 1$ and $4: 1)$ and total polymer concentration $(15-30 \% \mathrm{w} / \mathrm{v})$ on the fiber morphology, tensile properties, chemical and thermal properties of the APS-PCL composite scaffolds were investigated. Higher APS concentrations in the polymer blend resulted in formation of fused fibers and thus, increased fiber diameters. The degree of hydration and consequently, degradation rate of the scaffolds increased with the APS concentration. The FTIR and DSC studies showed selective loss of APS polymer from composite scaffolds after degradation. Scaffolds with 1:1 APS:PCL ratio exhibited maximum elastic modulus (EM) of 30 $\pm 2.5 \mathrm{MPa}$ compared to 0:1, 2:1 and 4:1 ratios. Increasing total polymer concentrations (15-30\% w/v) at constant (2:1) APS:PCL ratio increased stiffness and tensile strength of the electrospun 
scaffolds. Biocompatibility studies using C2C12 mouse myoblast cells showed enhanced cell spreading on APS containing scaffolds after 6h as compared to PCL-only scaffolds. Thus, the present study demonstrates successful development of APS-based thermoset elastomeric nanofibrous scaffolds by blending with semicrystalline PCL polymer for the first time. Tunable physicochemical, mechanical and degradation properties of these composite APS-PCL scaffolds will be further exploited for skeletal muscle tissue engineering applications.

Keywords Poly(1,3-diamino-2-hydroxypropane-co-polyol sebacate)(APS); Polycaprolactone (PCL), myoblasts, electrospinning, nanofibrous scaffolds 
TABLE OF CONTENTS

ACKNOWLEDGEMENTS _......................................................................................

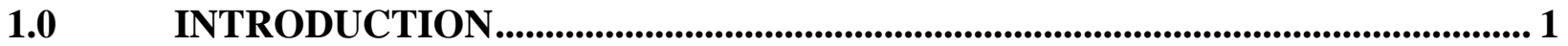

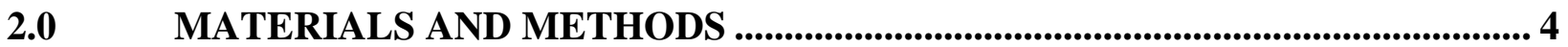

2.1 SYNTHESIS OF POLY (1,3-DIAMINO-2-HYDROXYPROPANE-CO-

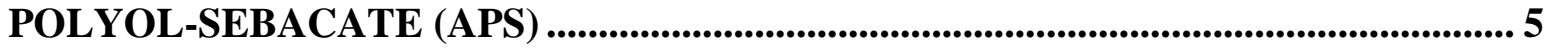

2.2 PREPARATION OF APS-PCL FIBROUS SCAFFOLDS .............................. 5

2.3 SCANNING ELECTRON MICROSCOPY ............................................................ 7

2.4 MECHANICAL PROPERTIES....................................................................... 7

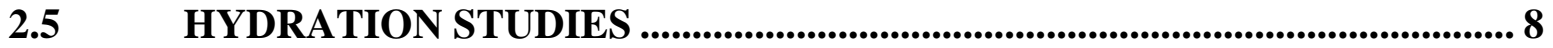

2.6 IN VITRO DEGRADATION ............................................................................. 8

2.7 FOURIER TRANSFORM INFRARED SPECTROSCOPY (FTIR) .............. 9

$2.8 \quad$ THERMAL CHARACTERIZATION.................................................................... 9

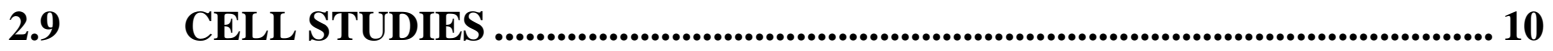

2.9.1 Cell culture ............................................................................................................... 10

2.9.2 Cell viability, adhesion and spreading.............................................................. 10

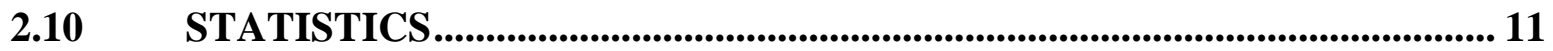

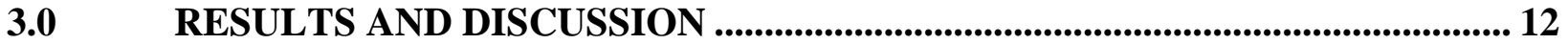


3.1 EFFECT OF POLYMER CONCENTRATION ON THE SCAFFOLD

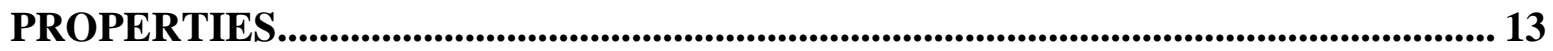

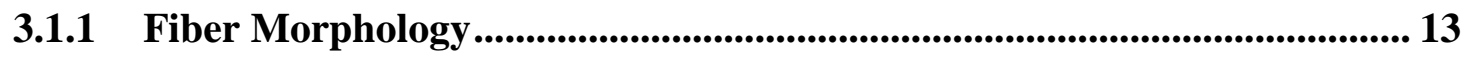

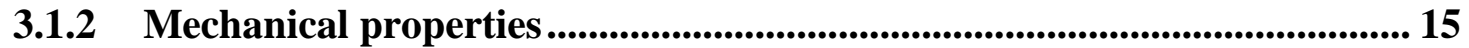

3.1.3 Hydration and degradation ................................................................. 15

3.2 EFFECT OF APS: PCL RATIO ON THE SCAFFOLD PROPERTIES .... 18

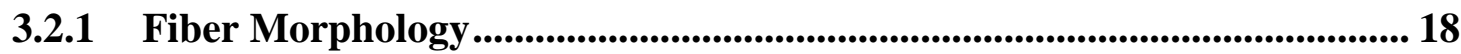

3.2.2 Fourier Transform Infrared Spectroscopy (FTIR) .................................... 20

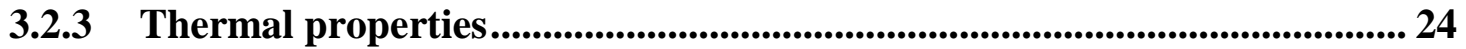

3.2.4 Mechanical properties ..................................................................................... 25

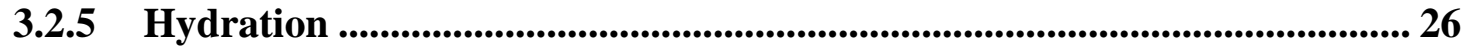

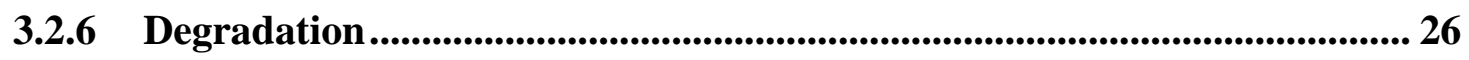

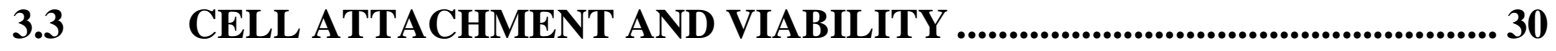

4.0 CONCLUSION AND FUTURE DIRECTION ................................................... 32

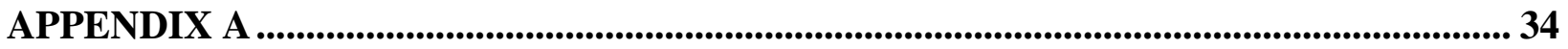

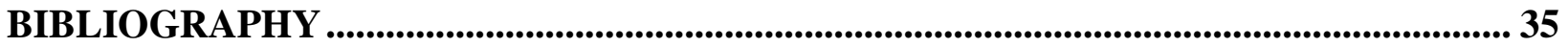




\section{LIST OF TABLES}

Table 1. Different formulations of APS-PCL fibrous scaffolds.......................................... 6 Table 2 Quantitative analysis of intensity ratio of amide to carbonyl peaks as a function of APS:

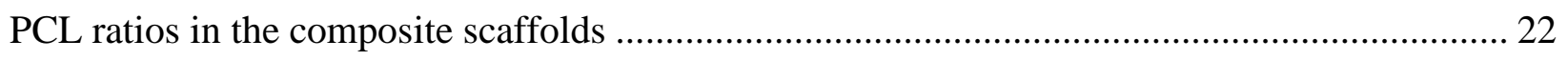

Table 3 Thermal properties of various APS: PCL scaffolds before or after degradation............. 25 


\section{LIST OF FIGURES}

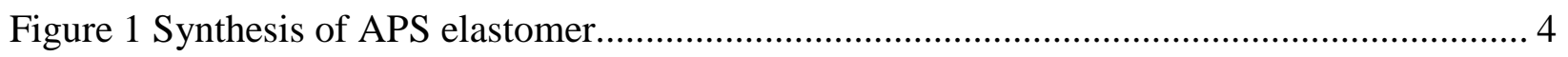

Figure 2 Effect of total polymer concentration on A) fiber morphology studied by scanning electron microscopy (white arrows indicate formation of fused fibers with increased polymer concentration) and B) fiber diameter distribution. (Significant differences at $\mathrm{p}<0.05$ compared to $15 \% \mathrm{w} / \mathrm{v}(*)$ and compared to $30 \% \mathrm{w} / \mathrm{v}(\#)$; One-way ANOVA followed by Tukey test for $\mathrm{n} \geq$ 100 fibers).

Figure 3 Effect of total polymer concentration on A) elastic modulus and ultimate tensile strength (UTS); B) hydration; C) degradation rate (mass loss) under accelerated condition $(0.05 \mathrm{M} \mathrm{NaOH})$; and $\mathrm{D})$ morphology of fibers before and after accelerated degradation. White arrows indicate formation of pores after degradation. ( $n=4-5$; Significant differences at $\mathrm{p}<0.05$

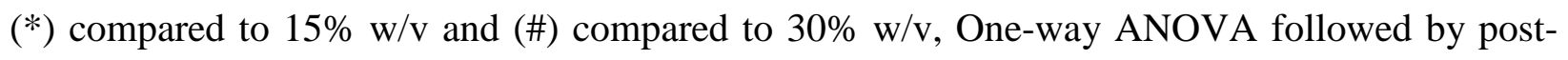
hoc Tukey test). 17

Figure 4 Effect of varying APS:PCL ratio on A) fiber morphology studied by scanning electron microscopy (SEM) and B) fiber diameter distribution. White arrows indicate fused fibers with increased APS concentration. (Significant differences at $\mathrm{p}<0.05 *$ compared to 0:1 and 1:1 APS:PCL scaffolds; \#: compared to 0:1, 1:1 and 2:1 scaffolds; One-way ANOVA followed by Tukey test for $n \geq 100$ fibers). 19 
Figure 5 Physicochemical, thermal and mechanical properties of APS-PCL composite scaffolds; A) Comparison of FTIR spectra of 0:1 (PCL), 1:1, 2:1 and 4:1 APS:PCL scaffolds with that of pure PCL and APS polymers; DSC thermograms showing B) heating cycle and C) cooling cycle of various scaffolds compared with APS polymer and 0:1 (PCL) scaffold; D) Elastic modulus (EM) and ultimate tensile strength (UTS) of APS-PCL scaffolds, n=5; E) Hydration properties of APS-PCL scaffolds after 24h immersion in Dulbecco's phosphate buffered saline (DPBS), $\mathrm{n}=4$ (Significant differences at $\mathrm{p}<0.05$ compared to *: 0:1, \#: 1:1 and \#\#: 2:1; One-way ANOVA

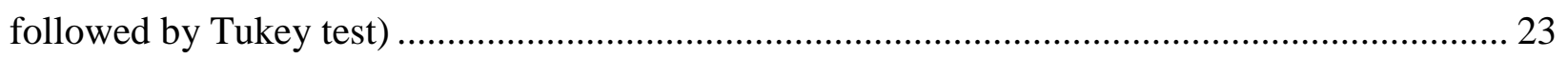
Figure 6 In vitro degradation studies A) Percentage mass loss of APS-PCL scaffolds under accelerated conditions after immersion in $0.05 \mathrm{M} \mathrm{NaOH}$ solution; (Significant differences at $\mathrm{p}<$ 0.05 compared to *: 0:1, \#: 1:1 and 2:1; One-way ANOVA followed by Tukey test for $n=4)$; B) Comparison of FTIR spectra of 0:1 (PCL) and 4:1 APS:PCL scaffolds before (solid lines) and after (dotted lines) degradation; C) Heating and D) cooling DSC thermograms of 0:1 (PCL) and 4:1 APS:PCL scaffolds before (solid lines) and after (dotted lines) degradation; E) Morphology of degraded (Day 5) 0:1, 1:1, 2:1 and 4:1 APS:PCL scaffolds compared to as-prepared (Day 0) scaffolds; white arrows indicate pore formation in degraded samples. 29 Figure 7 Adhesion and spreading of C2C12 mouse myoblast cells after A) 6h and B) 24h in culture. Cells were cultured on APS-PCL composite scaffolds for 6 and 24h respectively, fixed and actin cytoskeleton was stained with phalloidin (green) and nuclei stained with Hoechst (blue). Hydrophobic PCL scaffolds show round cell morphology at earlier time point of 6h whereas cells can easily spread on composite APS-PCL scaffolds by 6h. However, at later time point of 24h, no difference was observed in cell morphology on all the scaffolds including PCL. 
C) Metabolic activity (Alamar blue) of C2C12 cells on 0:1 and 4:1 APS:PCL scaffolds showing increased cell proliferation over 7 days on both, PCL as well as APS-PCL scaffolds................... 31 


\section{ACKNOWLEDGEMENTS}

I would like to express my sincere thanks and gratitude to University of Pittsburgh, School of Pharmacy, for giving me the opportunity to pursue my graduate studies. I thank my advisor Dr. Shilpa Sant from the bottom of my heart for guiding me throughout my graduate studies. I would like to thank my co-advisor Dr. Lisa C. Rohan and Dr. Vinayak Sant for their support and guidance.

I am immensely grateful to my parents, Mr. K.M. Mukundan and Mrs. P. Mythili, who have always been a great support and source of encouragement to me. Amma and Appa, thank you so much for being there for me, always.

I thank Mr. Jonathan Franks and Dr. Donna Stolz (Center for Biologic Imaging, University of Pittsburgh) for the Scanning electron microscopy facility. I sincerely thank Dr. Robert Gibbs and Mr. Doug Nelson (School of Pharmacy, University of Pittsburgh) for access to the confocal microscope. I thank Mr. Avinash Patil and Dr Elia Beniash (Center for dental and craniofacial regeneration, University of Pittsburgh) for training me on the Fourier Transform Infrared Spectroscopy. I sincerely thank Ms. Lin Wang and Ms. Galit Regev (Dr. Rohan's lab) for training me on the TA.XT (mechanical testing) and DSC (Differential Scanning Calorimetry) respectively. 
I thank my friends Akhil Patel, Dr. Manjulata Singh, Yingfei Xue, Yuzhe Chen, Sumit Goenka, Dr. Maria Jaramillo, Harini Krishnan, Jean Jr. Liu and other lab members from Dr. Sant's lab for their support and encouragement.

My sincere thanks to all the faculty, staff and fellow graduate students from the School of Pharmacy. 


\subsection{INTRODUCTION}

Tissue engineering aims to develop functional synthetic or biological substitutes to repair or replace damaged organs/tissues in the body [1]. For successful therapeutic tissue engineering, it is important to recreate biomimetic cellular microenvironments that consist of extracellular matrix (ECM), cells as well as biochemical and mechanical cues to promote tissue regeneration [2, 3]. Polymeric scaffold serves as an important component in the initial process of tissue regeneration by providing necessary mechanical support and extracellular matrix (ECM)mimetic three-dimensional environment to the cells in vitro and in vivo. A number of natural and synthetic polymers have been used to facilitate scaffold design for tissue engineering which include chitosan $[\underline{4}, \underline{5}]$, polyglycerol sebacate (PGS) [ㅇ-8], polycaprolactone (PCL) $[\underline{6}, \underline{9}$, polylactic acid (PLLA) [10, 11] etc. While natural biopolymers offer advantages like good biocompatibility, batch to batch variability in the properties limits their usefulness. On the other hand, synthetic polymers provide choice of wide variety of methods for scaffold fabrication and allow fine tuning of chemical, physical and mechanical properties suitable for regeneration of target tissue [12]. Of particular interest is the design of synthetic biodegradable elastomers with tunable physicochemical/ mechanical/ biological properties suitable for soft tissue engineering $[\underline{7}, \underline{13-16}]$. Such elastomeric scaffolds can promote regeneration of damaged soft tissues such as skeletal/cardiac muscles by providing dynamic mechanical environment experienced by cells in these tissues. 
There are two types of elastomeric materials,that can be used for scaffold fabrication. They are thermoplastic and thermoset elastomers. Thermoplastic elastomers, such as $\alpha$-hydroxyl polyesters, which include Polyglycolic acid (PGA), poly (L-lactic) acid (PLA) and the copolymer Polylactic-co-glycolic acid (PLGA) are approved for sutures[16]. These thermoplastic elastomers melt upon application of heat. Their degradation profile in vivo cannot be accurately predicted. Therefore, the structural integrity of the scaffolds can be lost with degradation, leading to decreased mechanical support to the cells adhered on the scaffold. Hence, there is a lot of focus on tailoring the mechanical and degradation properties of thermoplastic elastomers $[\underline{17}$, 18]. Recently, there are increasing applications of thermoset elastomers like PGS. Thermoset elastomers do not melt upon heating, once they are thermally cross-linked. The degradation of scaffolds in vivo can be predicted. Thus, structural integrity of scaffolds can be maintained, when thermoset elastomers are used. Some of the limitations of thermoset polymers are the amorphous and waxy nature of the polymers, which limit their application[19].

To date, biodegradable synthetic thermoset elastomer PGS has been widely explored for various tissue engineering applications $[\underline{6}, \underline{8}, \underline{20-30}]$. PGS exhibits faster degradation rate of $17 \%$ in 9 weeks in PBS, elastic modulus of around $0.282 \mathrm{MPa}$, and it's tensile strength is above 0.5 MPa [7, 31]. To prolong the degradation profile of PGS, Bettinger et al. synthesized Poly(1,3diamino-2-hydroxypropane-co-polyol sebacate)s (APS) [32]. APS elastomers are a class of biodegradable poly(ester amide)s consisting of amino alcohol-based cross-linked networks with tensile strength of $1 \mathrm{MPa}$, reversible elongations up to $92 \%$ and projected in vivo degradation half-lives of about 20 months [를 $\underline{33}]$. Although APS has better mechanical strength and longer degradation times than PGS, poor solubility of APS polymers in the most commonly used polar 
solvents such as ethanol, acetone and non-polar solvents like dichloromethane limit its utility. APS pre-polymer is only soluble in hexafluoroisopropyl alcohol (HFIP) [ $\underline{7}, \underline{16}, \underline{32}]$. Moreover, low viscosity of APS pre-polymer solution hampers it's processing into fibrous scaffolds that can mimic native ECM of many tissues. In general, poor solubility and amorphous waxy nature of the most thermoset elastomers has restricted their processing only to thermally cured smooth films [3] or microfabrication [34]. Recently, PGS has been blended with other materials such as polycaprolactone (PCL) []ㅡ, Poly(L-lactide) [35], gelatin [녀] and porcine urinary bladder matrix [36] to facilitate it's processing into ECM-mimicking nanofibrous scaffolds and to further improve their mechanical, biological and degradation properties.

PCL is a semicrystalline thermoplastic polyester with hydrophobic properties, slow degradation profile (over years) and poor cell attachment [ㅌ, 27, 37]. However, solubility in most common organic solvents and ease of processability into electrospun fibrous scaffolds has led to its widespread use in electrospinning. In our study, addition of small quantity of PCL to amorphous APS elastomer improved the solution viscosity. It was hypothesized that addition of PCL will facilitate fiber formation of APS while presence of APS will enhance hydrophilicity, degradation and cell adhesion properties of hydrophobic PCL. Here, we report fabrication and characterization of APS-based fibrous composite scaffolds by blending with small quantities of PCL. The effect of PCL addition on the physicochemical properties (hydration, in vitro degradation) and mechanical properties (elastic modulus and ultimate tensile strength) of APSPCL composite scaffolds are investigated. Biocompatibility of composite scaffolds was also investigated by seeding $\mathrm{C} 2 \mathrm{C} 12$ mouse myoblast cells on the composite scaffolds for future applications in skeletal muscle repair. 


\subsection{MATERIALS AND METHODS}

1,3-diamino-2-hydroxy-propane (DAHP), glycerol (G), sebacic acid (SA) and Poly (Ecaprolactone) (PCL, Mw 70-90 kDa) were purchased from Sigma-Aldrich (St. Louis, MO) and used as received. Hexafluoroisopropanol (HFIP) was obtained from Acros Organics. All other chemicals were purchased from Sigma-Aldrich unless otherwise mentioned. Cell culture supplies including media, trypsin-EDTA and antibiotics were obtained from Corning, unless otherwise mentioned.

$$
\text { APS synthesis scheme }
$$
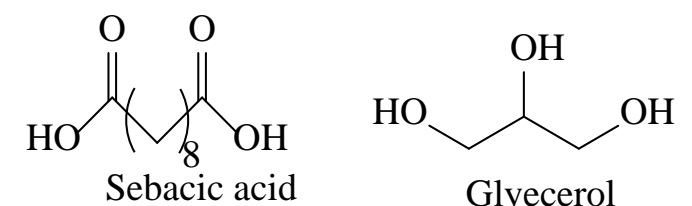<smiles>NCC(O)CN</smiles>

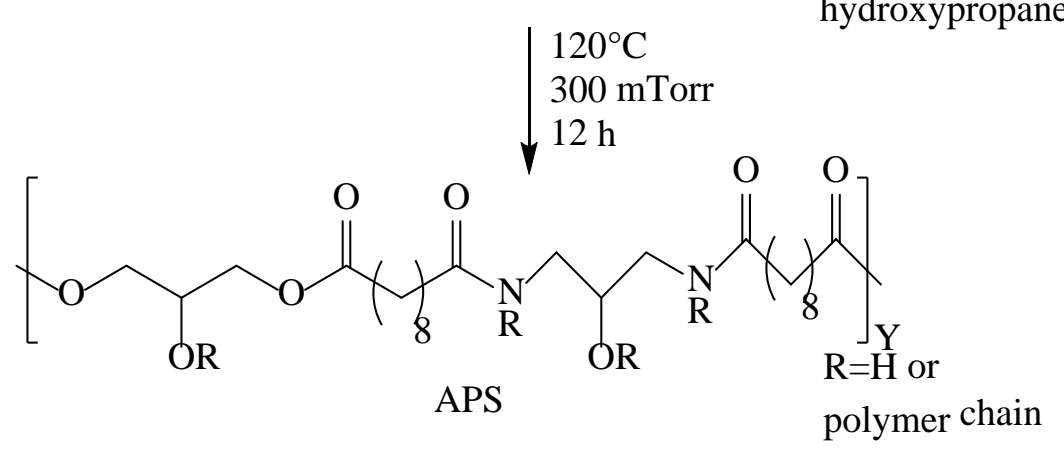

\section{1,3-diamino-2-} hydroxypropane 300 mTorr $12 \mathrm{~h}$

Figure 1 Synthesis of APS elastomer 


\subsection{SYNTHESIS OF POLY (1,3-DIAMINO-2-HYDROXYPROPANE-CO-POLYOL- SEBACATE (APS)}

APS elastomer with DAHP:G:SA ratio of 2:1:3 was synthesized as shown in Figure 1, following the procedure described earlier [32]. Briefly, DAHP, glycerol (G) and sebacic acid (SA) were charged in a dry round bottom flask in 2:1:3 molar ratios. The flask was sealed and heated in oil bath at $120^{\circ} \mathrm{C}$ for $1 \mathrm{~h}$ under inert atmosphere using Argon gas. The pressure was then slowly dropped to approximately $100 \mathrm{mTorr}$ and the reactants were allowed to react at $120^{\circ} \mathrm{C}$ for $10 \mathrm{~h}$ under constant stirring. At the end of the reaction, a semisolid, light yellow colored APS prepolymer elastomer was obtained and it was stored at $4^{\circ} \mathrm{C}$ until further use.

\subsection{PREPARATION OF APS-PCL FIBROUS SCAFFOLDS}

Composite APS-PCL fibrous scaffolds with different compositions were fabricated using a conventional electrospinning setup. Solvents such as dichloromethane, ethanol and acetone could not dissolve APS pre-polymer. APS pre-polymer is soluble only in HFIP, so HFIP was selected as solvent for dissolving APS and PCL. The fibers were collected on a wax paper placed on top of aluminum foil and dried in vacuum desiccator to evaporate residual organic solvent. Initially, effect of voltage (6, 10 and $12 \mathrm{kV}$ ) and collector to needle distance (6, 10 and $14 \mathrm{~cm})$ on fiber morphology was studied by keeping polymer concentration (22.5\%w/v), APS:PCL ratio (2:1) and distance $(10 \mathrm{~cm})$ or applied voltage $(10 \mathrm{kV})$ constant. These studies were used to determine the optimum voltage and collector to needle distance. Based on these initial studies, applied voltage of $10 \mathrm{kV}$ and distance of $10 \mathrm{~cm}$ were selected as optimum and kept constant during 
further studies. To study effect of APS:PCL ratio on the scaffold properties, APS and PCL were dissolved in HFIP at different weight ratios (1:1, 2:1 \& 4:1, respectively) keeping total polymer concentration constant at $22.5 \% \mathrm{w} / \mathrm{v}$. These solutions were electrospun at a constant voltage $(10 \mathrm{kV})$ and constant distance $(10 \mathrm{~cm})$ between the collector and needle. The effect of polymer concentration $(15,22.5$ and 30\% w/v) on fiber morphology was studied by keeping APS:PCL ratio, voltage, and distance constant at 2:1, 10kV and $10 \mathrm{~cm}$, respectively. Thus, total 6 scaffold formulations were prepared with varying APS:PCL ratio or total polymer concentrations as summarized in Table 1 . Needle diameter (21G), polymer solution flow rate $(1 \mathrm{ml} / \mathrm{h})$ and electrospinning time (40 min) were kept constant during all scaffold preparations. The scaffolds were stored in vacuum desiccator until further use.

Table 1. Different formulations of APS-PCL fibrous scaffolds

\begin{tabular}{|c|c|c|c|c|}
\hline Effect of & $\begin{array}{l}\text { Polymer concentration } \\
(\% \mathrm{w} / \mathrm{v})\end{array}$ & $\begin{array}{l}\text { APS:PCL } \\
\text { Ratio }\end{array}$ & $\begin{array}{l}\text { Distance } \\
\text { (cm) }\end{array}$ & $\begin{array}{l}\text { Voltage } \\
(\mathrm{kV})\end{array}$ \\
\hline \multirow{3}{*}{$\begin{array}{l}\text { Polymer } \\
\text { concentration }\end{array}$} & 15 & \multirow{3}{*}{$2: 1$} & \multirow{3}{*}{10} & \multirow{3}{*}{10} \\
\hline & 22.5 & & & \\
\hline & 30 & & & \\
\hline \multirow{4}{*}{ Polymer ratio } & \multirow{4}{*}{22.5} & 0:1 (PCL) & \multirow{4}{*}{10} & \multirow{4}{*}{10} \\
\hline & & $1: 1$ & & \\
\hline & & & & \\
\hline & & 4:1 & & \\
\hline
\end{tabular}




\subsection{SCANNING ELECTRON MICROSCOPY}

Effect of polymer concentration (15-30\% w/v) and APS:PCL ratio (0:1-4:1) on fiber morphology was studied using Field Emission scanning electron microscopy (JEOL 6335F). Fibrous scaffolds were sputter-coated with 5nm of gold-palladium using Cressington 108 auto sputtercoater and images were obtained using accelerated voltage of $3 \mathrm{kV}$ and a working distance of 8 $\mathrm{mm}$. The SEM images were analyzed using the NIH ImageJ software to quantify the fiber diameter. The fiber diameters of more than 100 fibers per sample were measured and box plots were used to determine the effect of each factor (polymer concentrations and APS: PCL ratios) on the fiber diameter distribution.

\subsection{MECHANICAL PROPERTIES}

The uniaxial tensile testing was performed using the Texture Analyzer (TA-XT plus). The

rectangular scaffolds ( 15 x $5 \mathrm{~mm}^{2}, \mathrm{n}=5$ ) were tested using a load cell of $10 \mathrm{~N}$ and crosshead speed of $10 \mathrm{~mm} / \mathrm{min}$ until fracture. Elastic modulus (EM) was calculated from the slope of linear region (1-8\%) of stress-strain curve and ultimate tensile strength (UTS) of the scaffolds is reported as the highest stress value at the scaffold failure. 


\section{$2.5 \quad$ HYDRATION STUDIES}

Effect of various polymer concentrations and APS:PCL ratios on water absorption capacity of the scaffolds was investigated via hydration studies. The scaffolds $\left(2 \times 1 \mathrm{~cm}^{2}, \mathrm{n}=4\right)$ were immersed in Dulbecco's phosphate buffered saline (DPBS) for $24 \mathrm{~h}$ at $37^{\circ} \mathrm{C}$ in a water bath shaker. The percentage hydration was estimated by using the formula,

$\%$ Hydration $=\left[\left(\mathrm{W}_{t}-\mathrm{W}_{0}\right) / \mathrm{W}_{0} \times 100\right.$,

where $\mathrm{W}_{0}$ is initial scaffold weight $(\mathrm{t}=0)$ and $\mathrm{W}_{t}$ is hydrated scaffold weight $(\mathrm{t}=24 \mathrm{~h})$.

\subsection{IN VITRO DEGRADATION}

In vitro degradation rate of scaffolds was studied under accelerated conditions using $0.05 \mathrm{M}$ sodium hydroxide $(\mathrm{NaOH})$ at $37^{\circ} \mathrm{C}$ in a water bath shaker. The scaffolds $\left(2 \times 2 \mathrm{~cm}^{2}, \mathrm{n}=4\right)$ were immersed in $0.05 \mathrm{M} \mathrm{NaOH}$ solution and the mass loss was studied over a period of 5 days by measuring the weight of the samples on day 0 and on pre-determined time points $(1,2,3$ and 5 days). The percentage mass loss was calculated using the formula,

$\%$ Mass loss $=\left[\left(\mathrm{W}_{0}-\mathrm{W}_{t}\right) / \mathrm{W}_{0}\right] \times 100$

The samples were then rinsed with distilled water, lyophilized and used further for SEM imaging, chemical and thermal characterization as described below. 


\section{$2.7 \quad$ FOURIER TRANSFORM INFRARED SPECTROSCOPY (FTIR)}

Effect of APS:PCL ratio and accelerated degradation study on chemical composition of the scaffolds was studied using FTIR spectroscopy with attenuated total reflection (ATR-FTIR). The spectra were recorded in absorption mode with a resolution of $4 \mathrm{~cm}-1$ using Bruker Vertex 70 FTIR spectrometer. The final results are presented as an average of 256 scans. The peaks were analyzed using the Spectra Viewer Software (Perkin Elmer).

\subsection{THERMAL CHARACTERIZATION}

The thermal properties of the scaffolds before and after degradation were determined by differential scanning calorimetry (DSC, Mettler Toledo 1 STARe System). One to four mg of the sample was weighed in sealed aluminum pans. The samples were initially heated at a rate of $10^{\circ} \mathrm{C} / \mathrm{min}$ from $25^{\circ} \mathrm{C}$ to $150^{\circ} \mathrm{C}$, followed by cooling from $150^{\circ} \mathrm{C}$ to $-70^{\circ} \mathrm{C}$ and subsequent heating from $-70^{\circ} \mathrm{C}$ to $150^{\circ} \mathrm{C}$. Data analysis was done using STARe software Version 11.00. Pure APS pre-polymer, PCL polymer and PCL scaffolds (0:1) were used as controls to correlate effects of APS:PCL ratio before and after degradation on the thermal properties such as the melting point ( $\left.T_{m}\right)$, crystallization temperature $\left(T_{c}\right)$, melting $\left(\Delta H_{m}\right)$ and crystallization $\left(\Delta H_{c}\right)$ enthalpies. 


\subsection{CELL STUDIES}

\subsubsection{Cell culture}

The mouse myoblast cells (C2C12) ATCC (CRL-1772 ${ }^{\mathrm{TM}}$ ) were obtained from Dr. Adam Feinberg's lab (Carnegie Mellon University, Pittsburgh PA). The cells were cultured in Dulbecco’s Modified Eagle Medium (DMEM, Corning cellgro

Bovine Serum (FBS, Hyclone, Thermofisher Scientific) and 1\% Penicillin/Streptomycin (Corning cellgro isopropanol under UV light for 30 min, washed with DPBS thrice and seeded with C2C12 cells using a seeding density of 70,000 cells $/ \mathrm{cm}^{2} /$ scaffold. The media was changed every day and the scaffolds were stained for actin-phalloidin staining as described below.

\subsubsection{Cell viability, adhesion and spreading}

The scaffolds seeded with C2C12 cells were fixed in 4\% paraformaldehyde solution (30 min) after $6 \mathrm{~h}$ and $24 \mathrm{~h}$ in culture to study cell adhesion and spreading. The scaffolds were then washed with DPBS thrice, followed by blocking and permeabilization using $5 \%$ bovine serum albumin (BSA) containing $0.1 \%$ Triton $\mathrm{X}-100$ in PBS for $1 \mathrm{~h}$. The phalloidin staining was done using Alexa Flour Phalloidin 647 (Cell Signaling Technologies) in 1:20 dilution in PBS containing 1\% BSA. The scaffolds were incubated with conjugated antibody for $30 \mathrm{~min}$ at room temperature and then washed with PBS containing 0.1\% Triton X-100. Cell nuclei were stained using the Hoechst dye and confocal images were obtained using inverted confocal laser scanning microscope (Olympus Fluoview 1000) under 20X and 40X objectives. 
The cell proliferation was studied on 0:1 (PCL) and 4:1 APS:PCL scaffolds over a period of 7 days using Alamar Blue Assay (Invitrogen) according to the manufacturer's protocol. The Alamar Blue assay is an indicator of metabolic activity of the cells and it can be used to study the time-dependent proliferation of the cells, based on their ability to reduce resoruzin (blue) to resorufin (pink). Cell-seeded scaffolds $(n=5)$ were treated with $10 \%$ v/v Alamar Blue in growth media at pre-determined time and incubated for $4 \mathrm{~h}$ at $37^{\circ} \mathrm{C}$. The fluorescence intensity was then measured using microplate reader (Gen5 Biotek) at excitation/emission wavelengths of 530/590 $\mathrm{nm}$. Alamar Blue solution in media $(10 \% \mathrm{v} / \mathrm{v})$ incubated without any cells were used for blank correction.

\subsection{STATISTICS}

The results are represented as mean \pm standard deviation ( $\mathrm{n}=4-5$ from 2-3 independent experiments). The statistical significance between multiple groups was analyzed using One-way

or Two-way ANOVA for multiple comparisons followed by Tukey post-hoc analysis (OriginPro8 SRO v. 8.07). The $p$ values less than 0.05 were considered statistically significant. 


\subsection{RESULTS AND DISCUSSION}

The APS-PCL scaffolds were electrospun by varying processing conditions such as total polymer concentration, ratios of individual polymers, applied voltage and the collector-needle distance. Electrospun fibers could not be formed at low polymer concentration (less than $15 \% \mathrm{w} / \mathrm{v}$ ) due to low solution viscosity causing dripping from the needle. On the other hand, fiber formation was not observed at high concentrations of polymer (more than $30 \% \mathrm{w} / \mathrm{v}$ ) due to high solution viscosity. Hence polymer concentrations between $15 \%$ and $30 \% \mathrm{w} / \mathrm{v}$ were considered for the present study. When applied voltage was varied, fibers could not be formed below $6 \mathrm{kV}$ whereas splitting of fibers was observed at voltage above $14 \mathrm{kV}$. Although fibers could be produced using voltages between $6-14 \mathrm{kV}$, continuous and uniform fibers with narrow fiber diameter distribution were obtained at $10 \mathrm{kV}$ (data not shown). Thus, voltage of $10 \mathrm{kV}$ was selected as optimum voltage in this study. Similarly, when collector to needle distance was varied, fibers were obtained between $8-12 \mathrm{~cm}$ distances. Smaller distance $(8 \mathrm{~cm})$ resulted in fusion of fibers and broad fiber diameter distribution $(0.3-1.6 \mu \mathrm{m})$ whereas distances at 10 and $12 \mathrm{~cm}$ resulted in reasonably narrow fiber diameter distribution (0.6-1.2 $\mu \mathrm{m}$; data not shown). Hence, further studies were conducted with $10 \mathrm{~cm}$ distance between the collector and needle, which was an intermediate point in the range tested. The effects of total polymer concentration and APS: PCL ratios on the properties of the elastomeric composite scaffolds are summarized below. 


\subsection{EFFECT OF POLYMER CONCENTRATION ON THE SCAFFOLD PROPERTIES}

In this study, HFIP was used as common solvent for electrospinning APS and PCL solutions due to the limited solubility of APS in other organic solvents. Fibers were electrospun by varying total polymer concentration ranging from $15 \%$ to $30 \% \mathrm{w} / \mathrm{v}$, keeping other parameters such as ratio of the APS:PCL (2:1), voltage $(10 \mathrm{kV})$, distance between needle and collector $(10 \mathrm{~cm})$, flow rate $(1 \mathrm{~mL} / \mathrm{h})$ and needle diameter $(21 \mathrm{G})$ constant. The concentration range was selected based on the solution viscosity and ability to form continuous fibers by electrospinning. The solution viscosity was too low below $15 \% \mathrm{w} / \mathrm{v}$ and too high above $30 \% \mathrm{w} / \mathrm{v}$ polymer concentration impeding continuous fiber formation. Hence, scaffolds were fabricated by varying total polymer concentration between $15-30 \% \mathrm{w} / \mathrm{v}$.

\subsubsection{Fiber Morphology}

The SEM images and fiber diameter distribution of APS-PCL scaffolds prepared by varying total polymer concentration are shown in Figure 2A and 2B, respectively. It was observed that fiber diameter increased with polymer concentration. Indeed, the median fiber diameter increased from $0.4 \mu \mathrm{m}$ for $15 \% \mathrm{w} / \mathrm{v}$ to around $2 \mu \mathrm{m}$ for $30 \% \mathrm{w} / \mathrm{v}$ polymer concentration (Figure $2 \mathbf{B}$ ). As reported in the literature, increase in polymer concentration results in higher solution viscosities and enhanced polymer chain entanglements leading to increase in the fiber diameters [38-42]. Similarly, higher polymer concentration also exhibited broad fiber diameter distribution profiles $(1-3.5 \mu \mathrm{m})$ for $30 \% \mathrm{w} / \mathrm{v}$ scaffolds compared to narrow diameter distribution $(0.2-1.2 \mu \mathrm{m})$ for $15 \%$ w/v scaffolds. The broad fiber diameter distribution may result from incomplete/slower drying 
and thus, fusion of fibers at higher solution viscosity (white arrows, Figure 2A). Our results are in accordance with Stankus et al.[43] who also reported increased fiber diameters of poly(ester urethane)urea with increasing polymer concentrations possibly due to increased solution viscosity.
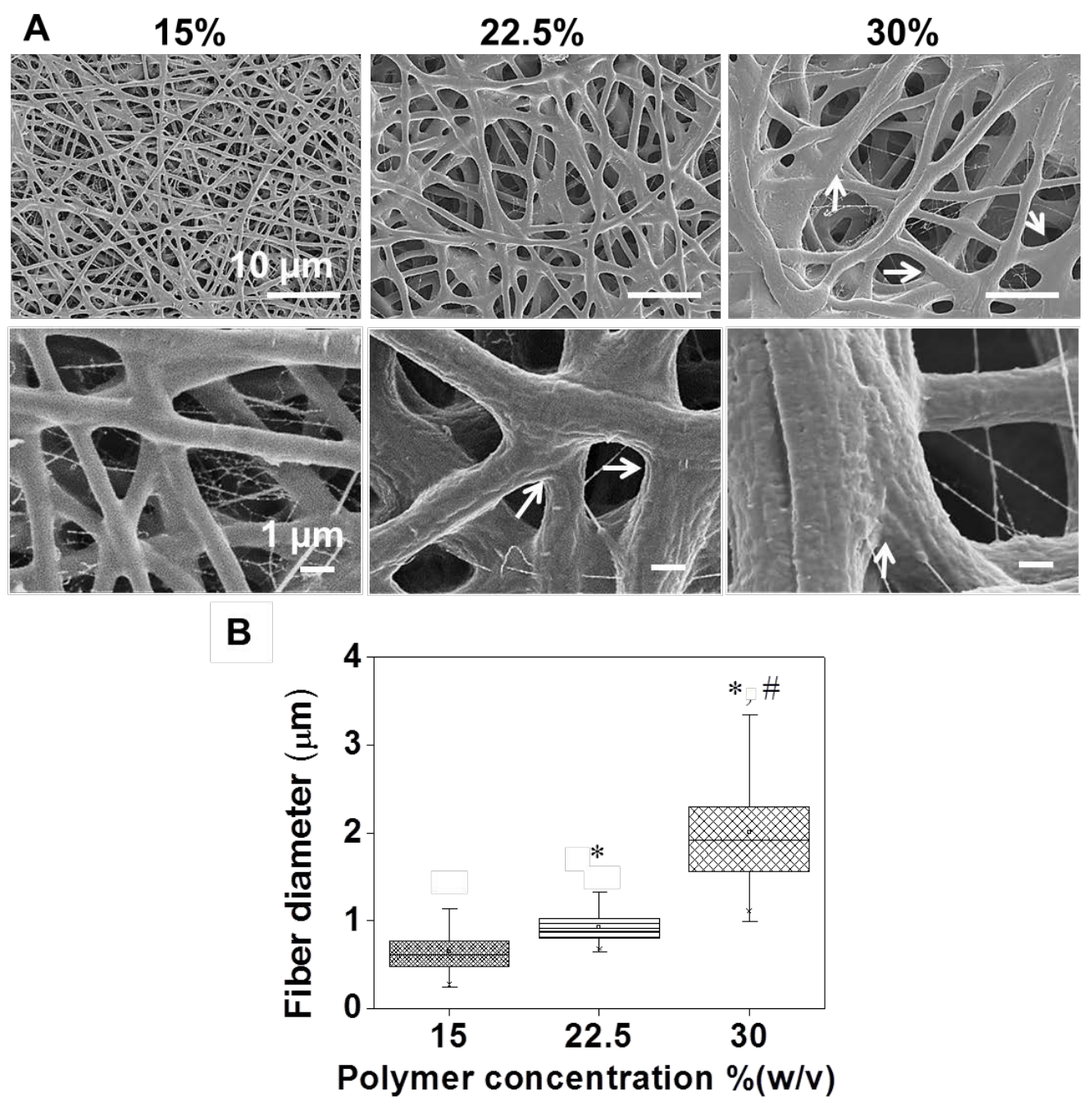

Figure 2 Effect of total polymer concentration on A) fiber morphology studied by scanning electron microscopy (white arrows indicate formation of fused fibers with increased polymer concentration) and B) fiber diameter distribution. (Significant differences at $\mathrm{p}<0.05$ compared to $15 \% \mathrm{w} / \mathrm{v}\left(^{*}\right.$ ) and compared to 30\% w/v (\#); One-way ANOVA followed by Tukey test for $\mathrm{n} \geq 100$ fibers). 


\subsubsection{Mechanical properties}

We also investigated effect of polymer concentration on mechanical properties of the APS-PCL scaffolds (Figure 3A). Elastic moduli of the scaffolds with 15 and $22.5 \% \mathrm{w} / \mathrm{v}$ polymer

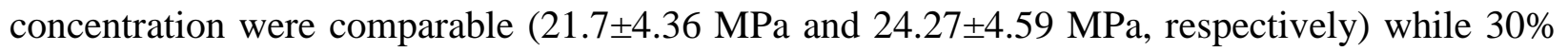
w/v polymer scaffolds showed a three-fold increase in the elastic modulus $(p<0.05$, compared to 15 and 22.5\% w/v, One-way ANOVA). The ultimate tensile strength (UTS) (Figure 3A) showed opposite trend where the scaffolds with $15 \%$ w/v polymer concentration exhibited significantly

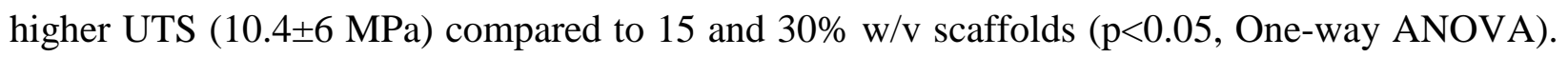
Thus, higher polymer concentration led to higher elastic modulus suggesting increased scaffold stiffness, which in turn led to faster failure and decreased tensile strength. This mechanical behavior may be attributed to formation of thicker fibers due to their fusion (Figure 2, white arrows). Similar decrease in tensile strength with increase in fiber diameter has been reported earlier for electrospun scaffolds of PCL and PVDF [ㄴ4, $\underline{45}]$.

\subsubsection{Hydration and degradation}

The water absorption capacity of scaffolds is an important measure of scaffold hydrophilicity as it can affect rate of scaffold degradation as well as cell attachment. Indeed, hydration serves as the first step to degradation. The percent hydration of APS-PCL scaffolds at different polymer concentrations is shown in Figure 3B. Scaffolds prepared with $22.5 \% \mathrm{w} / \mathrm{v}$ polymer concentration showed significantly higher $(\mathrm{p}<0.05)$ degree of hydration as compared to $15 \%$ and $30 \% \mathrm{w} / \mathrm{v}$ concentration while $30 \% \mathrm{w} / \mathrm{v}$ polymer scaffold exhibited least hydration implying increased hydrophobicity (Figure 3B) with higher polymer concentration. 
The fibrous scaffolds are made of physical mixture of APS and PCL in the present study. In this combination, PCL is a slowly degrading polymer and follows acid or base-catalyzed bulk degradation mechanism [37]. APS has been shown to degrade by hydrolysis in vivo via hydrolases, esterases and proteases, and the crosslinking degree plays a significant role in its degradation [33]. The APS polymer with low crosslinking degree was found to be more susceptible to degradation [32, 33]. Here, we investigated the effect of addition of uncrosslinked APS pre-polymer on the degradation rate of APS-PCL composite scaffolds. Due to slow degrading nature of PCL, the study was conducted using $0.05 \mathrm{M} \mathrm{NaOH}$ to accelerate degradation of scaffolds. The degradation rate of scaffolds prepared by varying polymer concentration (15$30 \% \mathrm{w} / \mathrm{v})$ at constant APS:PCL ratio (2:1) is shown in Figure 3C. It was observed that degradation rate decreased with increasing total polymer concentrations. On day 5, scaffolds prepared with $15 \% \mathrm{w} / \mathrm{v}$ polymer concentration showed $61.9 \pm 3.4 \%$ mass loss while those made of $30 \% \mathrm{w} / \mathrm{v}$ polymer concentration exhibited only $36.4 \pm 2.7 \%$ mass loss in $0.05 \mathrm{M} \mathrm{NaOH}$ solution (Figure 3C). The mass loss results correlated well with the hydration study, where $30 \% \mathrm{w} / \mathrm{v}$ polymer scaffolds had least water uptake (Figure 3B) and hence, the least mass loss. It should be noted that $30 \% \mathrm{w} / \mathrm{v}$ scaffolds also exhibited higher fiber diameters with broad diameter distribution (Figure 2). This may also have contributed to the decreased hydration and slower degradation due to lower surface area. The SEM images of scaffolds after 5 days degradation showed enhanced roughness on the surface of $15 \% \mathrm{w} / \mathrm{v}$ scaffolds and pore formation in case of 22.5 and 30\% w/v scaffolds (Figure 3D, white arrows) confirming changes in fiber morphology due to degradation. Overall, polymer concentration had an impact on scaffold morphology (fiber size distribution), elastic modulus, hydration rate and degradation rate. Considering all these variables, $22.5 \% \mathrm{w} / \mathrm{v}$ polymer concentration generated uniform fibrous scaffolds with highest 
degree of hydration and intermittent degradation rate. This polymer concentration was used further to study the effect of APS: PCL ratio on scaffold properties.
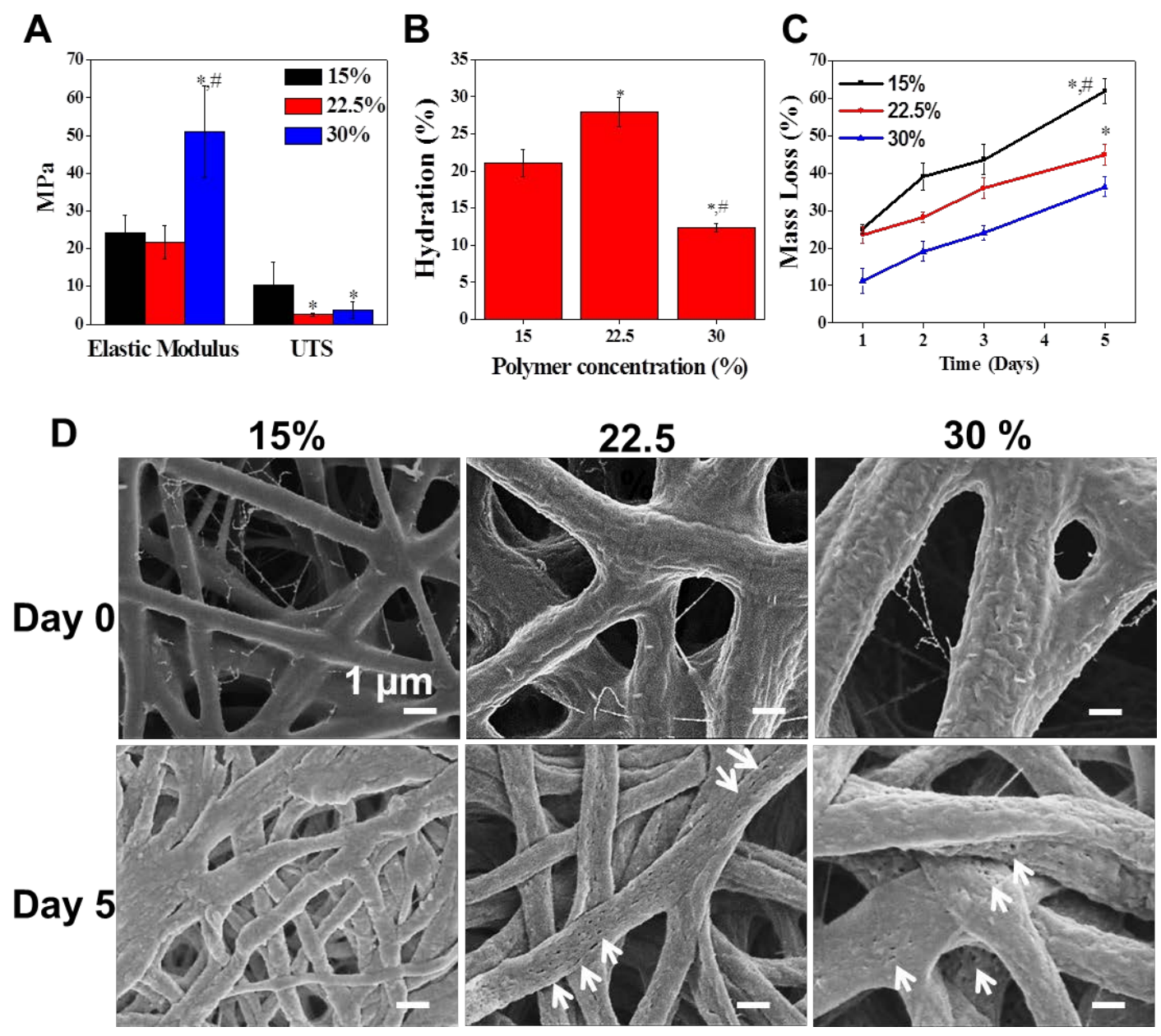

Figure 3 Effect of total polymer concentration on A) elastic modulus and ultimate tensile strength (UTS);

B) hydration; C) degradation rate (mass loss) under accelerated condition (0.05M NaOH); and D) morphology of fibers before and after accelerated degradation. White arrows indicate formation of pores after degradation. ( $\mathrm{n}=4-5$; Significant differences at $\mathrm{p}<0.05(*)$ compared to $15 \% \mathrm{w} / \mathrm{v}$ and $(\#)$ compared to $30 \% \mathrm{w} / \mathrm{v}$, One-way ANOVA followed by post-hoc Tukey test). 


\subsection{EFFECT OF APS: PCL RATIO ON THE SCAFFOLD PROPERTIES}

The effect of APS: PCL ratio on the fiber morphology was studied at 1:1, 2:1 and 4:1 APS: PCL ratios at constant polymer concentration $(22.5 \% \mathrm{w} / \mathrm{v})$, voltage $(10 \mathrm{kV})$, distance between needle and collector $(10 \mathrm{~cm})$, flow rate $(1 \mathrm{~mL} / \mathrm{h})$ and needle diameter $(21 \mathrm{G})$. As more than $15 \% \mathrm{w} / \mathrm{v}$ PCL concentrations could not be electrospun due to high solution viscosity, pure PCL scaffolds (denoted as 0:1) were fabricated using 15\% w/v PCL and used as a control for all further experiments.

\subsubsection{Fiber Morphology}

The SEM images and distribution of fiber diameters for scaffolds of varying APS:PCL ratios are shown in Figure 4A and 4B, respectively. APS-PCL scaffolds prepared with 0:1 and 1:1 ratio did not have significant effect on the fiber diameter with median diameter of $1.2 \mu \mathrm{m}$ (range of 0.8$1.4 \mu \mathrm{m}$ ) (Figure 4B). Increasing the ratio of APS:PCL to 2:1 and 4:1 resulted in the fusion of the fibers (white arrows, Figure 4A) and significantly broader size distribution compared to lower APS concentrations (Figure 4B, $\mathrm{p}<0.05$ One-way ANOVA). These findings are in accordance with the previous studies where fiber diameters of composite electrospun PGS-PCL scaffolds also increased with increasing proportion of PGS [27]. This may be due to waxy nature of both APS and PGS pre-polymers and their low electrospinnability. 

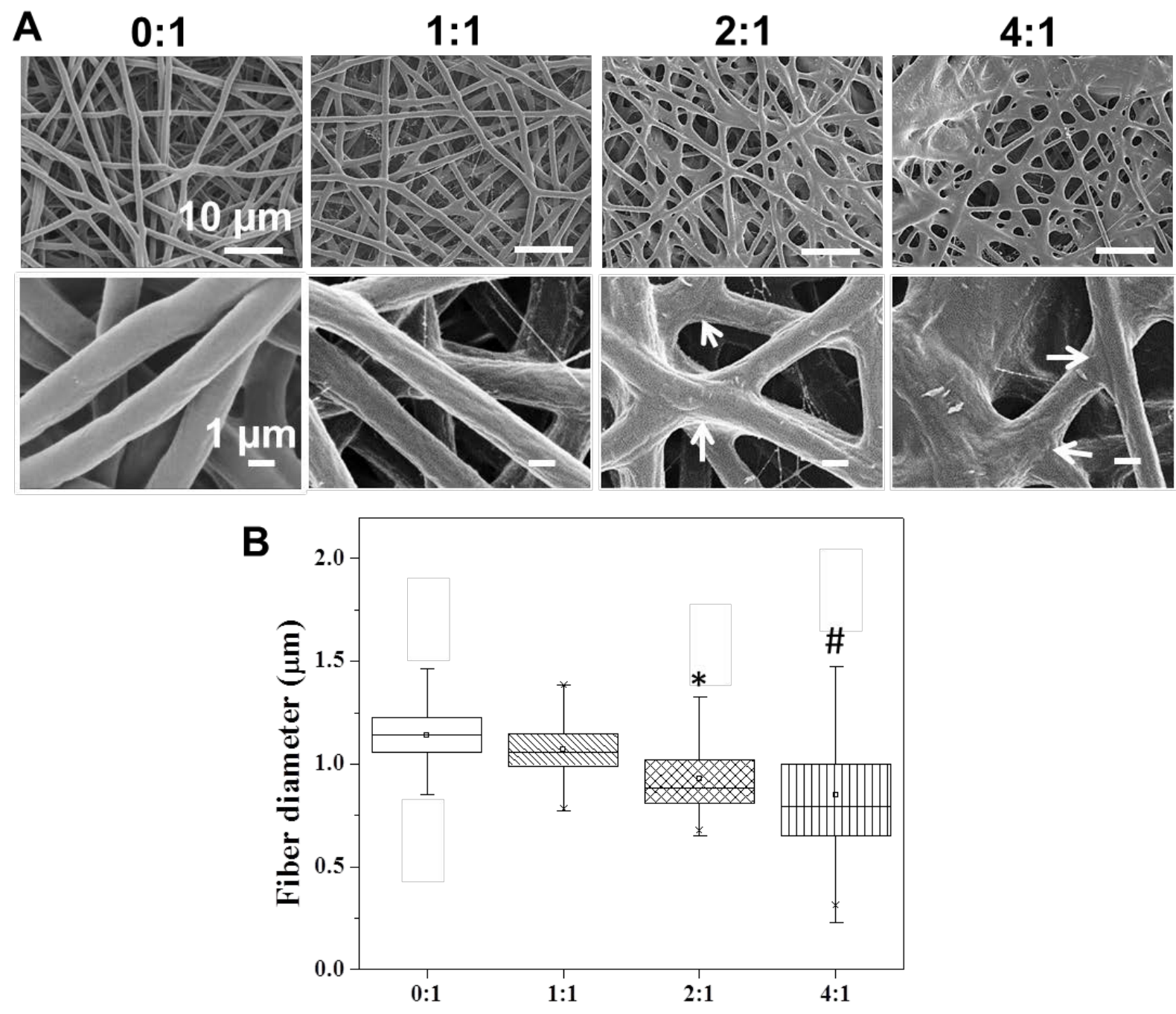

Figure 4 Effect of varying APS:PCL ratio on A) fiber morphology studied by scanning electron microscopy (SEM) and B) fiber diameter distribution. White arrows indicate fused fibers with increased APS concentration. (Significant differences at p $<0.05$ *compared to 0:1 and 1:1 APS:PCL scaffolds; \#: compared to 0:1, 1:1 and 2:1 scaffolds; One-way ANOVA followed by Tukey test for $n \geq 100$ fibers). 


\subsubsection{Fourier Transform Infrared Spectroscopy (FTIR)}

To study specific intermolecular interactions between APS and PCL as well as effect of electrospinning on crystalline structure of the polymers, FTIR of APS-PCL electrospun scaffolds for 1:1, 2:1 and 4:1 ratios was compared with that of PCL polymer, APS polymer and electrospun PCL (0:1) scaffold (Figure 5A). The FTIR spectra of PCL polymer showed absorption peaks corresponding to carbonyl stretching in the amorphous phase $\left(1734 \mathrm{~cm}^{-1}\right)$ (blue shaded box in Figure 5A) and asymmetric COC stretching $\left(1242 \mathrm{~cm}^{-1}\right)$ [46, $\left.\underline{47}\right]$. In addition to the characteristic PCL peaks, PCL scaffolds also showed two new peaks at $1188 \mathrm{~cm}^{-1}$ and $1167 \mathrm{~cm}^{-1}$ corresponding to OC-O and symmetric COC stretching [46], which were not evident in PCL polymer spectrum (green shaded box in Figure 5A). As pointed out by Coleman et al. [48], these absorption peaks are associated with ordered conformation of the PCL chains and are sensitive to orientation of polymer chains. Thus, appearance of these peaks in electrospun PCL scaffolds implies that electrospinning may have changed the orientation of PCL chains. In case of 1:1, 2:1 and 4:1 APS:PCL scaffolds, absorption peak at $1188 \mathrm{~cm}^{-1}$ was weak whereas symmetric COC stretching peak at $1167 \mathrm{~cm}^{-1}$ shifted to $1170-1174 \mathrm{~cm}^{-1}$. The same peak was also observed in pure APS polymer although at higher wavenumber $\left(1176 \mathrm{~cm}^{-1}\right)$. In addition, pure APS polymer showed carbonyl stretching $\left(1731 \mathrm{~cm}^{-1}\right)$, primary amine (NH2 scissors, $\left.1642 \mathrm{~cm}^{-1}\right)$, secondary amide peaks (N-H in plane bend at $1556 \mathrm{~cm}^{-1}$ and $\mathrm{C}-\mathrm{N}$ stretch at $1261 \mathrm{~cm}^{-1}$ ) as reported earlier [32]. These amine/amide peaks were absent in the spectra of PCL polymer as well as electrospun PCL scaffold. However, all the APS-PCL scaffolds with varying APS ratio showed presence of amine/amide peaks at $1642 \mathrm{~cm}^{-1}$ and $1556 \mathrm{~cm}^{-1}$ (Red shaded box, Figure 5A), along with characteristic PCL peak around $1240 \mathrm{~cm}^{-1}$ (asymmetric COC stretching). Compared with pure 
PCL polymer, intensity ratio of peaks at $1642 \mathrm{~cm}^{-1}$ (primary amine) and $1724 \mathrm{~cm}^{-1}$ (carbonyl stretching) increased with increasing APS concentration in the blend (Table 2).

These results confirm presence of both APS and PCL in the composite APS-PCL scaffolds. Interestingly, carbonyl stretching peak in amorphous phase of pure PCL polymer shifted from $1734 \mathrm{~cm}^{-1}$ to $1724 \mathrm{~cm}^{-1}$ in all electrospun scaffolds including PCL (0:1), signifying formation of crystalline phases in scaffolds $[\underline{46}, \underline{48}, \underline{49}$. In addition, all electrospun scaffolds including PCL (0:1) exhibited a new peak at $1294 \mathrm{~cm}^{-1}$ corresponding to C-C and C-O stretching in crystalline phases (blue shaded boxes, Figure 5A) [느, $\underline{48}, \underline{49}$. Taken together, these observations suggest that the electrospinning process led to increase in the crystallinity of scaffolds as compared to pure PCL and APS polymers. However, the intensity of the peak at $1294 \mathrm{~cm}^{-1}$ decreased with increasing APS concentration in the blend (Figure 5A). This suggests that higher APS concentration decreased crystallinity in the composite scaffolds. Interestingly, no new peaks or significant peak shifts other than the characteristic APS \& PCL peaks were observed in the composite scaffolds, indicating lack of new molecular interaction between APS and PCL during electrospinning. This implies that the composite scaffolds are physical blends of APS and PCL polymers without any significant intermolecular interaction between them. 
Table 2 Quantitative analysis of intensity ratio of amide to carbonyl peaks as a function of APS: PCL ratios in the composite scaffolds

\begin{tabular}{|l|l|l|}
\hline \multirow{2}{*}{ Composition } & \multicolumn{2}{|c|}{ Intensity ratio } \\
\cline { 2 - 3 } & $\begin{array}{l}\text { Primary Amine }(1642 \\
\left.\mathrm{cm}^{-1}\right): \mathrm{C}=\mathrm{O}\left(1724 \mathrm{~cm}^{-1}\right)\end{array}$ & $\left.\begin{array}{l}\text { Secondary Amide }\left(1556 \mathrm{~cm}^{-}\right. \\
1\end{array}\right)$ C=O $\left(1724 \mathrm{~cm}^{-1}\right)$ \\
\hline $0: 1$ & NA & NA \\
\hline $1: 1$ & 0.49 & 0.72 \\
\hline $2: 1$ & 0.73 & 1.11 \\
\hline $4: 1$ & 1.06 & 1.55 \\
\hline APS & 2.12 & 3.42 \\
\hline
\end{tabular}




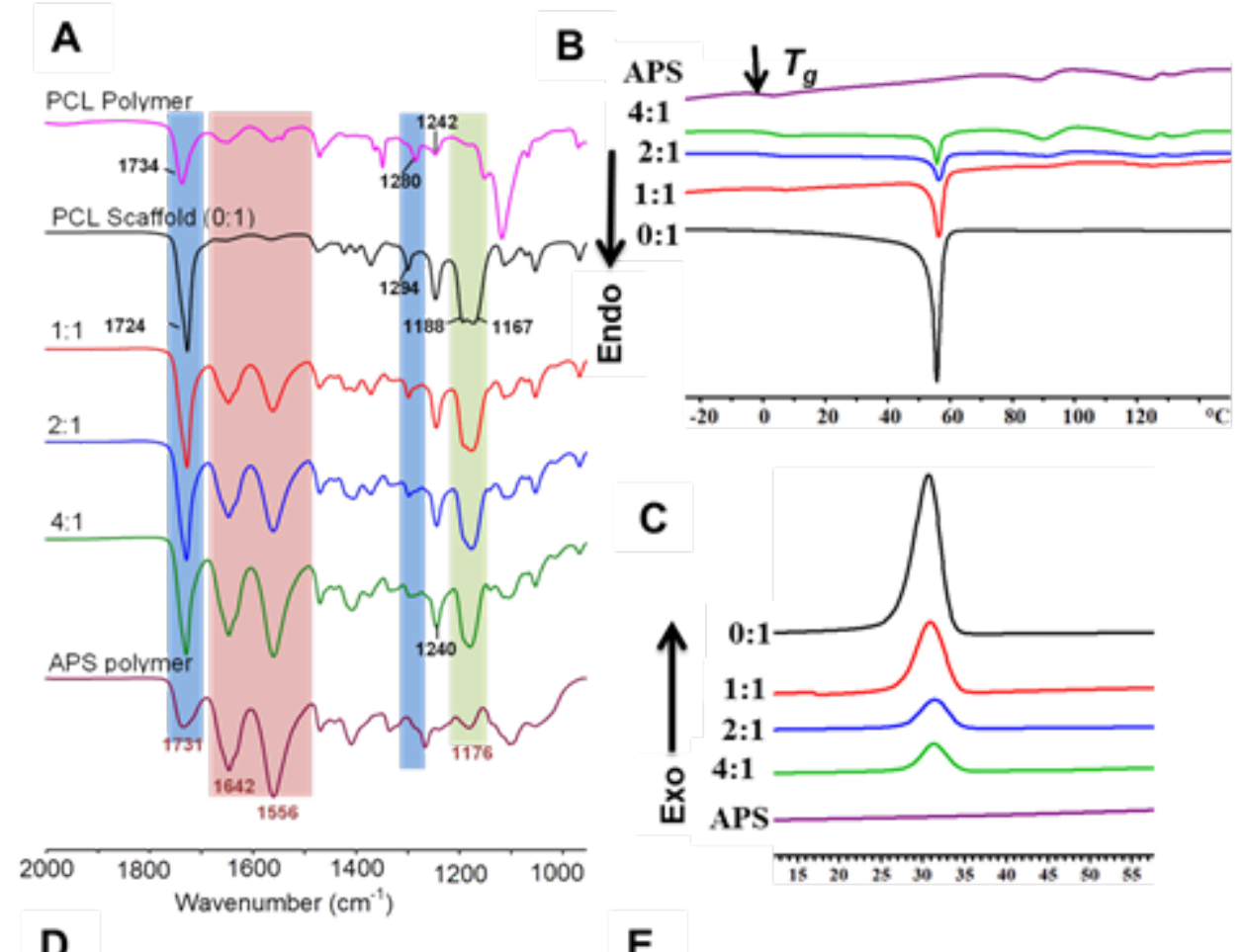

D
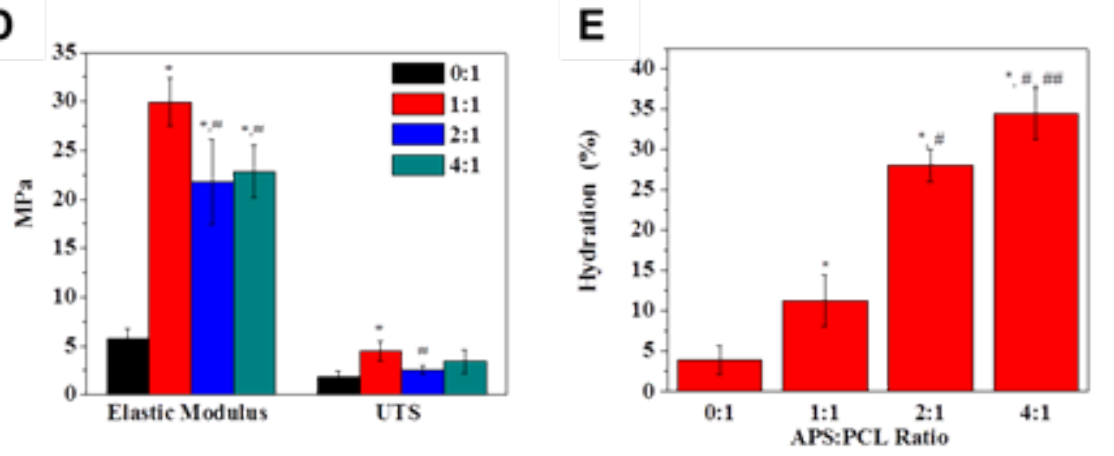

Figure 5 Physicochemical, thermal and mechanical properties of APS-PCL composite scaffolds; A) Comparison of FTIR spectra of 0:1 (PCL), 1:1, 2:1 and 4:1 APS:PCL scaffolds with that of pure PCL and APS polymers; DSC thermograms showing B) heating cycle and C) cooling cycle of various scaffolds compared with APS polymer and 0:1 (PCL) scaffold; D) Elastic modulus (EM) and ultimate tensile strength (UTS) of APS-PCL scaffolds, n=5; E) Hydration properties of APS-PCL scaffolds after 24h immersion in Dulbecco's phosphate buffered saline (DPBS), $\mathrm{n}=4$ (Significant differences at $\mathrm{p}<0.05$ compared to *: 0:1, \#: 1:1 and \#\#: 2:1; One-way ANOVA followed by Tukey test) 


\subsubsection{Thermal properties}

Effect of APS concentration on thermal properties of scaffolds was evaluated using differential scanning calorimetry (DSC). Figures 5B and 5C show the DSC thermograms of APS polymer and electrospun scaffolds for second heating (endothermic) and cooling (exothermic) cycles, respectively and corresponding thermodynamic data is listed in Table 3. Pure APS polymer exhibited glass transition $\left(T_{g}\right)$ around $-0.72^{\circ} \mathrm{C}$ whereas $T_{g}$ of PCL in electrospun scaffold was below $-50^{\circ} \mathrm{C}$. APS polymer showed multiple endothermic melting peaks $\left(T_{m}\right)$ around $89^{\circ} \mathrm{C}$ and $123^{\circ} \mathrm{C}$ whereas PCL scaffold showed single $T_{m}$ at $55^{\circ} \mathrm{C}$. The $T_{g}$ of composite APS-PCL scaffolds was found to be shifted to $4-5^{\circ} \mathrm{C}$; however, there was no significant change in their $T_{m}$. In fact, all composite scaffolds exhibited $T_{m}$ peaks corresponding to pure APS polymer or PCL scaffolds (Figure 5B, Table 3). Similarly, single exothermic peak corresponding to crystalline PCL phase was evident around $30-31^{\circ} \mathrm{C}$ in all electrospun scaffolds (Figure 5C, Table 3); however, the peak intensity decreased with increasing APS concentration. These observations confirm FTIR data that APS-PCL composite scaffolds are immiscible blends exhibiting properties of individual APS and PCL polymers and there was no molecular interaction between the two polymers. It should be noted that there was decrease in the melting $\left(\Delta H_{m}\right)$ and crystallization $\left(\Delta H_{c}\right)$ enthalpies with increasing weight fraction of APS polymer indicating reduced crystallinity and PCL chain mobility in the composite APS-PCL scaffolds as reported earlier [49, $\underline{50]}$. PCL is a semicrystalline polymer whereas APS is amorphous in nature. Therefore, it is anticipated that higher ratio of amorphous APS reduced semi-crystalline PCL proportion in the blend. For instance, 4:1 APS:PCL scaffold contained only 20\% PCL whereas 1:1 APS:PCL had 50\% PCL proportion. Thus, higher amount of APS in the blend reduced overall crystallinity of the blend thereby reducing crystallization enthalpies in a concentration-dependent manner. Similar trend were 
observed for melting enthalpy $\left(\Delta H_{m}\right)$ also suggesting reduced mobility of PCL chains in presence increasing concentrations of APS polymer in scaffolds [49, $\underline{50]}$. In fact, $\Delta H_{m}$ of 4:1 scaffold was almost 5-6 times lower than PCL scaffolds and identical to that of APS polymer (Table 3). Taken together, DSC results confirm FTIR results suggesting that APS and PCL are physically blended in the APS-PCL composite scaffolds.

Table 3 Thermal properties of various APS: PCL scaffolds before or after degradation

\begin{tabular}{|c|c|c|c|c|c|c|c|c|}
\hline \multirow{2}{*}{ 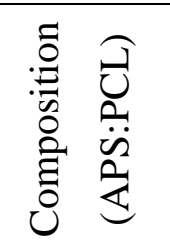 } & \multicolumn{2}{|c|}{$\mathrm{T}_{\mathrm{c}}\left({ }^{\circ} \mathrm{C}\right)$} & \multicolumn{2}{|c|}{$\Delta \mathrm{H}_{\mathrm{c}}(\mathrm{J} / \mathrm{g})$} & \multicolumn{2}{|c|}{$\mathrm{T}_{\mathrm{m}}\left({ }^{\circ} \mathrm{C}\right)$} & \multicolumn{2}{|c|}{$\Delta \mathrm{H}_{\mathrm{m}} \mathrm{PCL}(\mathrm{J} / \mathrm{g})$} \\
\hline & Before & After & Before & After & Before & After & Before & After \\
\hline $0: 1$ & 30.6 & 30.4 & 55.4 & 50.9 & 55.6 & 56.2 & 59.6 & 58.9 \\
\hline $1: 1$ & 30.9 & 33.6 & 24.3 & 59.7 & 56.1 & 59.5 & 19.7 & 67.2 \\
\hline 2:1 & 31.4 & 33.1 & 10.2 & 54.4 & 56.2 & 58.4 & 10 & 63.4 \\
\hline $4: 1$ & 31.3 & 32.5 & 8.8 & 47.6 & 55.6 & 57.6 & 8.37 & 57.7 \\
\hline $\begin{array}{c}\text { APS } \\
\text { polymer }\end{array}$ & NA & NA & NA & NA & $\begin{array}{l}88.5 \\
123.7\end{array}$ & NA & - & - \\
\hline
\end{tabular}

\subsubsection{Mechanical properties}

The mechanical properties (elastic modulus and ultimate tensile strength) of various APS-PCL composite scaffolds are shown in Figure 5D. Addition of APS to APS-PCL scaffolds even at 1:1 APS:PCL ratio led to higher stiffness values. Elastic moduli of all APS containing scaffolds (APS:PCL ratios of 1:1, 2:1 and 4:1) increased significantly $(\mathrm{p}<0.05)$ as compared to PCL scaffolds (0:1 APS:PCL). A similar trend was observed with UTS, where pure PCL scaffolds (0:1 APS:PCL) showed lowest UTS. This is in accordance with previous findings where increase in PGS concentration led to a 3-4 fold increase in the elastic moduli of PGS-PCL scaffolds [27]. 
Higher mechanical properties of APS-PCL scaffolds may be attributed to the complex interplay between crystallinity (DSC data) and fiber diameter distribution/ fiber morphology (fusion of fibers and formation of wedges, thus further enhancing the reinforcement of the scaffolds [27, 37].

\subsubsection{Hydration}

Effect of varying APS:PCL ratios on hydration of the scaffolds is shown in Figure 5E. Increasing APS amount in the polymer scaffolds significantly enhanced degree of hydration, with 4:1 APS:PCL scaffolds showing the maximum hydration $(\mathrm{p}<0.05)$. This may be attributed to decreased scaffold crystallinity (decreased $\Delta H_{c}$ and $\Delta H_{m}$, Table 3 ) due to addition of APS and more hydrophilic nature of APS due to presence amine groups as compared to PCL). Indeed, high hydrophilicity of APS-containing scaffolds prevented from getting meaningful contact angle measurements on these scaffolds. However, the contact angle of PCL (0:1) scaffold was found to be $135^{\circ}$ whereas that of thermally cured APS films was about $55^{\circ}$ supporting our observation of higher hydrophilicity and thus, hydration of APS-containing scaffolds. Lack of $T_{c}$ in the DSC thermograms of APS further confirms the amorphous nature of APS. Indeed, degree of crystallinity, polymer chain flexibility and hydrophilicity have been known to affect the degradation rate of biodegradable elastomers [14].

\subsubsection{Degradation}

The in vitro degradation rate of different APS:PCL scaffolds were monitored under accelerated conditions using $0.05 \mathrm{M} \mathrm{NaOH}$ and the change in mass loss is shown in Figure 6A. PCL 
scaffolds ( $0: 1$ ratio) showed least degradation in 5 days with mass loss of $12.5 \pm 4.9 \%$. Addition of APS accelerated the scaffold degradation rate with 4:1 APS:PCL showing maximum mass loss (86 $\pm 2.3 \%)$ in 5 days. This could be attributed to decrease in the crystallinity ((decreased $\Delta H_{c}$ and $\Delta H_{m}$, Table 3 ) and increase in the rate of hydration of scaffolds (Figure 4E) by addition of APS in scaffolds. Also, the scaffolds prepared in present study contain uncured (uncrosslinked) APS pre-polymer and it is reported that uncured pre-polymer of APS have faster degradation rate than its crosslinked counterparts [33]. As discussed in earlier section 3.2.3, higher concentration of APS also reduced $\Delta H_{m}$ indicating reduced crystallinity and increased polymer chain flexibility of the composite scaffolds, which may lead to faster degradation rate as compared to crystalline polymers [14]. Similar behavior has been reported for amorphous polymers such as poly(d,llactic-co-glycolic acid) (PLGA) which degrade faster than crystalline poly(l-lactic acid) (PLA) microspheres based on differences in their morphology [51]. In order to confirm that APS is indeed responsible for accelerating the degradation rate of the scaffolds, FTIR spectra of degraded scaffolds (0:1 and 4:1 ratios; dotted lines) was compared with their corresponding spectra before degradation (solid lines).

As shown in Figure 6B, 0:1 (pure PCL) scaffolds did not show significant differences in the FTIR spectra before or after degradation. However, peak intensity of primary $\left(1642 \mathrm{~cm}^{-1}\right)$ and secondary $\left(1556 \mathrm{~cm}^{-1}\right)$ amine groups in 4:1 APS:PCL scaffolds decreased significantly after degradation while there was very little change in carbonyl stretching peak at $1724 \mathrm{~cm}^{-1}$. Indeed, ratio of intensities of primary and secondary amine to carbonyl stretching in ester $\left(1724 \mathrm{~cm}^{-1}\right)$ in degraded samples of $4: 1$ scaffolds were found to be 0.22 and 0.57 respectively as compared to non-degraded scaffolds (1.06 and 1.55). Thus, FTIR data suggests preferential degradation of APS pre-polymer from the composite scaffolds. To further confirm this observation, we 
investigated thermal properties of degraded scaffolds. There was little effect on melting temperature $\left(T_{m}\right)$ and melting enthalpy $\left(\Delta H_{m}\right)$ as well as crystallization temperature $\left(T_{c}\right)$ and crystallization enthalpy $\left(\Delta H_{c}\right)$ before or after degradation for pure PCL scaffolds (0:1 ratio) as shown in Table 3 and Figure 6C. On the other hand, $T_{c}, \Delta H_{c}, T_{m}$, and $\Delta H_{m}$ values of composite APS-PCL scaffolds increased significantly after degradation compared to those before degradation suggesting increased crystallinity. Notably, $\Delta H_{m}$ and $\Delta H_{c}$ became identical to PCL scaffold (Table 3 and Figures 6C, 6D) further suggesting preferential degradation of APS prepolymer from the APS-PCL scaffolds. Similar trend of increased crystallinity was observed for polymers such as PGA by You et al. [52]. It was observed that amorphous regions in the electrospun PGA were preferentially degraded before the crystaline phase leading to increased crystallinity during degradation [52]. Similar observation was reported for poly(3hydroxybutyrate) (PHB), and poly(3-hydroxybutyrate-co-23\%-3-hydroxyvalerate) (PHB/V) with a clear preference for amorphous polymeric chains during initial phase of enzymatic degradation [53]. The change in surface morphology of scaffolds after degradation was determined by SEM as shown in Figure 6E. It can be seen that morphology of PCL (0:1 ratio) scaffolds before or after degradation study was similar without appearance of any surface pores. However, surface porosity in composite APS-PCL scaffolds after degradation increased with increasing APS concentration in scaffolds (white arrows, Figure 6E). This also correlated well with the mass loss results shown in Figure 6A, where scaffolds with higher APS concentration showed faster degradation rate. Furthermore, FTIR and DSC studies also confirmed preferential loss of APS from composite scaffolds suggesting that APS plays a considerable role in promoting degradation of APS-PCL scaffolds. This increased degradation rate of amorphous portion of the 
blend can be exploited to tailor the degradation rate of APS-PCL scaffolds for a suitable tissue engineering application.

A

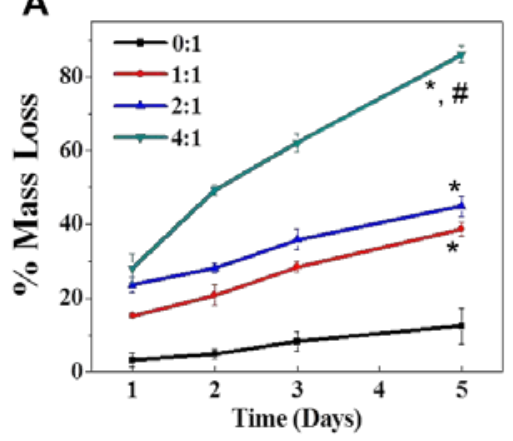

\section{Heating cycle}

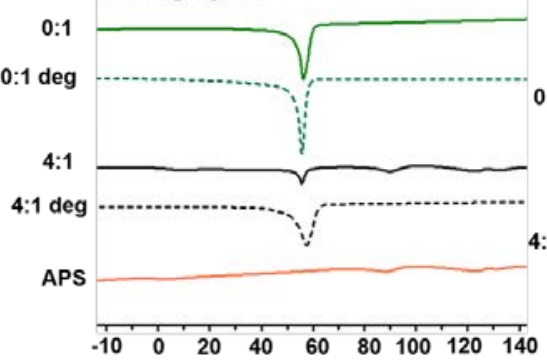

E

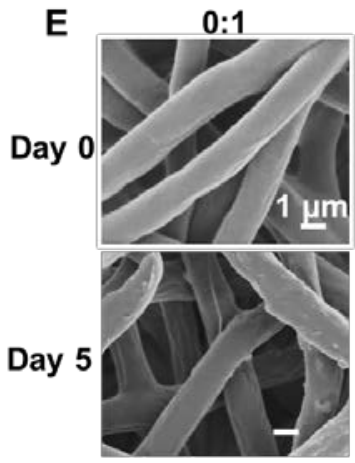

B

$1: 1$
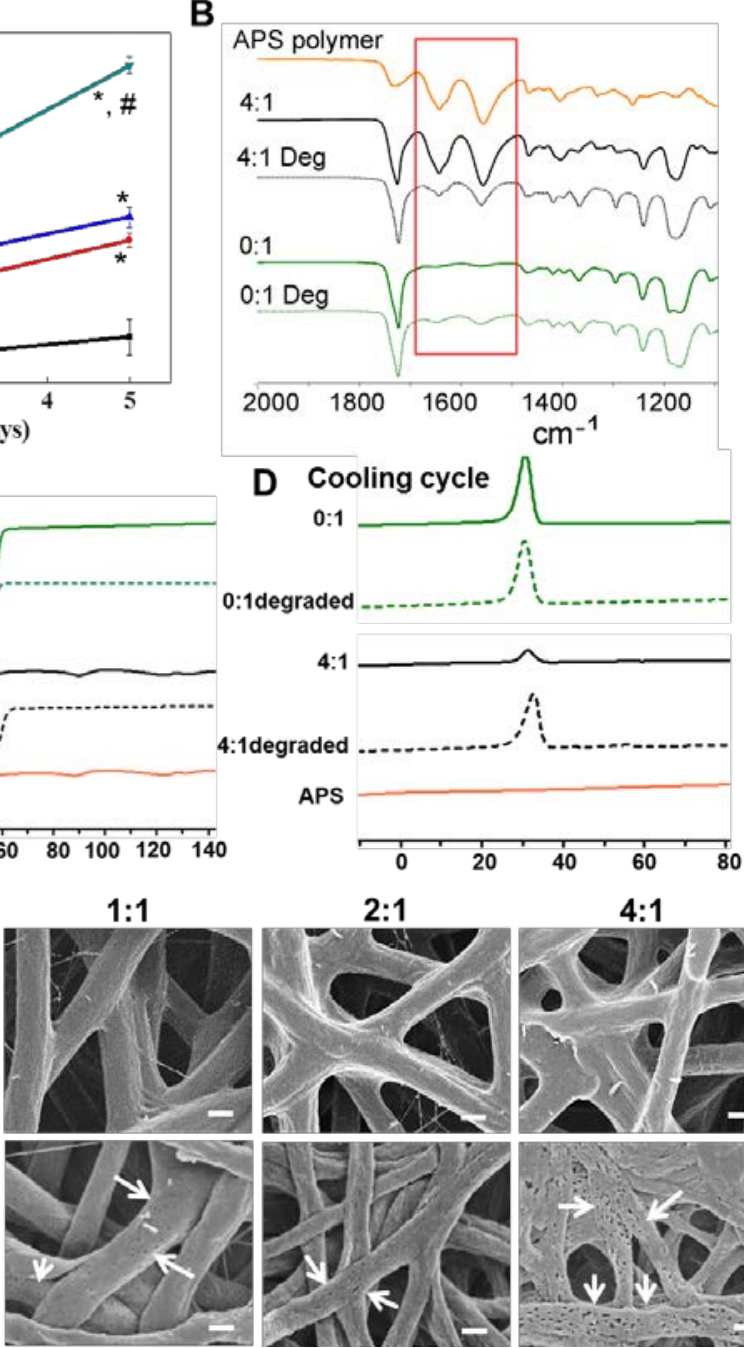

2:1

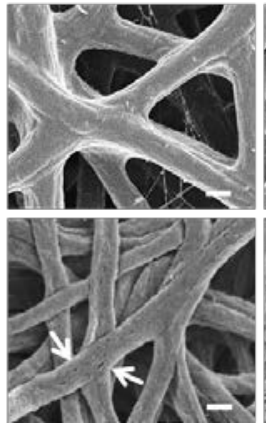

4:1

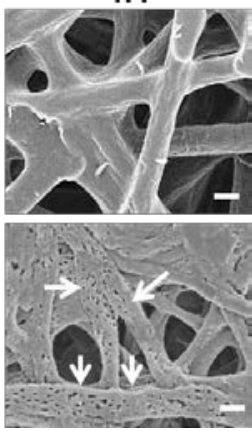

Figure 6 In vitro degradation studies A) Percentage mass loss of APS-PCL scaffolds under accelerated conditions after immersion in $0.05 \mathrm{M} \mathrm{NaOH}$ solution; (Significant differences at $\mathrm{p}<0.05$ compared to *: 0:1, \#: 1:1 and 2:1; One-way ANOVA followed by Tukey test for $n=4)$; B) Comparison of FTIR spectra of 0:1 (PCL) and 4:1 APS:PCL scaffolds before (solid lines) and after (dotted lines) degradation; C) Heating and D) cooling DSC thermograms of 0:1 (PCL) and 4:1 APS:PCL scaffolds before (solid lines) and after (dotted lines) degradation; E) Morphology of degraded (Day 5) 0:1, 1:1, 2:1 and 4:1 APS:PCL scaffolds compared to as-prepared (Day 0) scaffolds; white arrows indicate pore formation in degraded samples. 


\subsection{CELL ATTACHMENT AND VIABILITY}

In order to target any material for biomedical applications, biocompatibility is a very critical factor. Earlier, there have been lot of studies showing that the cell attachment and viability can be improved using polymer blends or nanoparticles $[\underline{6}, \underline{24}, \underline{26}, \underline{27}, \underline{54}]$. PCL is a hydrophobic polymer that exhibit poor cell attachment [27, 37]. Previous studies on APS have shown good cell viability and adhesion on thermally cured APS films [32]. In order to determine if addition of APS to the APS-PCL composite scaffolds had any effect on cellular adhesion, spreading and growth, cellular behavior of C2C12 mouse myoblasts were studied by immunostaining and metabolic activity assay and the results are depicted in Figure 7. The phalloidin staining for actin cytoskeleton after 6h showed that addition of APS promoted faster spreading of C2C12 cells while the cells seeded on PCL (0:1) were still round after 6h (Figure 7A).

This shows that presence of APS in APS: PCL scaffold facilitates cell spreading as early as $6 \mathrm{~h}$ after cell seeding. Faster adhesion and spreading of cells to the scaffold is advantageous for tissue engineering applications where time for cells to get integrated with the scaffold plays an important role. However, by 24h, C2C12 cells seeded on all composite and PCL (0:1) scaffolds exhibited spreading (Figure 7B). Metabolic activity of the cells seeded on the scaffolds containing 0:1 and 4:1 APS: PCL was studied by Alamar blue assay. APS:PCL (4:1) scaffolds exhibited slightly reduced metabolic activity at earlier time point of 24h suggesting lower cell attachment on 4:1 composite scaffold. However, at later time points, both 0:1 (PCL) and 4:1 APS:PCL scaffolds promoted cell proliferation as shown in Figure 7C. These results are in accordance with previous cell attachment and viability studies conducted on thermally cured APS films [32]. 

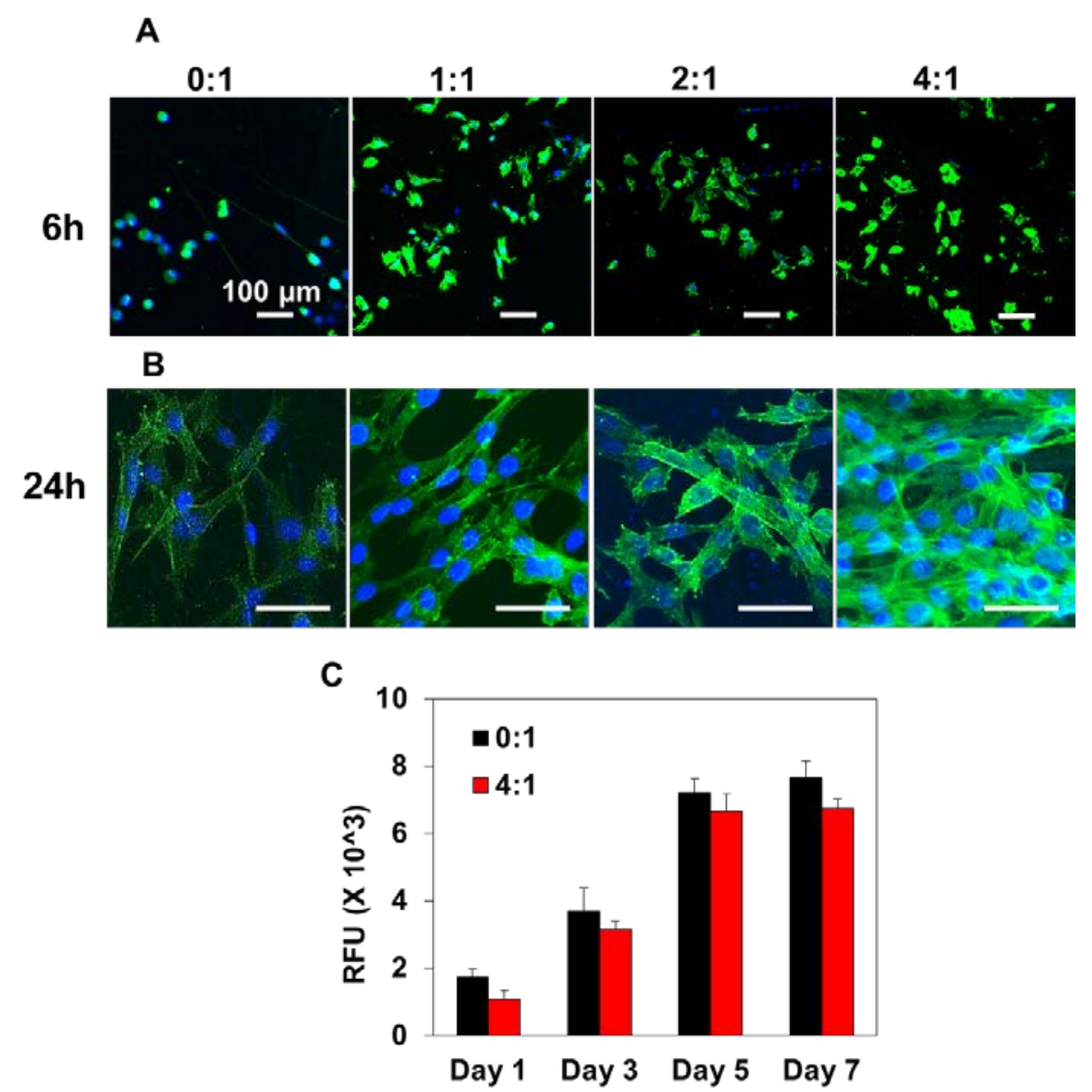

Figure 7 Adhesion and spreading of C2C12 mouse myoblast cells after A) 6h and B) 24h in culture. Cells were cultured on APS-PCL composite scaffolds for 6 and 24h respectively, fixed and actin cytoskeleton was stained with phalloidin (green) and nuclei stained with Hoechst (blue). Hydrophobic PCL scaffolds show round cell morphology at earlier time point of $6 \mathrm{~h}$ whereas cells can easily spread on composite APS-PCL scaffolds by $6 \mathrm{~h}$. However, at later time point of 24h, no difference was observed in cell morphology on all the scaffolds including PCL. C) Metabolic activity (Alamar blue) of C2C12 cells on 0:1 and 4:1 APS:PCL scaffolds showing increased cell proliferation over 7 days on both, PCL as well as APS-PCL scaffolds 


\subsection{CONCLUSION AND FUTURE DIRECTION}

In conclusion, elastomeric nanofibrous scaffolds of APS pre-polymer can be successfully fabricated by blending with PCL, a biodegradable polymer. The electrospun scaffolds can be prepared with up to $80 \% \mathrm{w} / \mathrm{w}$ APS concentration. The APS addition significantly enhanced mechanical properties of the scaffolds and increased their degradation rate. Further, these APS:PCL scaffolds supported adhesion, spreading and viability of C2C12 cells in vitro. These scaffolds can be promising candidates for skeletal muscle regeneration based on their improved physicochemical and mechanical properties.

Regeneration of skeletal muscle is significantly improved by two cues, 1. Alignment and 2. Electrical stimulation. Alignment cues in the scaffolds enable them to mimic the structure of in vivo skeletal muscle. This can be done by electrospinning method using two parallel plates collectors designed to provide the necessary difference in potential and thereby collecting highly aligned fibers between them[5].

Another important cue for skeletal muscle differentiation is electrical conductivity. As reported in literature, upon electrical stimulation, increased myogenic differentiation is observed. Thus, these scaffolds can be loaded with nanoparticles such as carbon nanotubes (CNT) and graphene oxide to increase electrical conductivity of the scaffolds. These particles have been shown to promote myoblast differentiation and also provide a platform which is electrically conductive [56-58]. Hence, upon myoblast cell seeding and adhesion, the scaffolds can be electrically 
stimulated[59]. This will enable the APS-PCL scaffolds to be a promising candidate for skeletal muscle tissue engineering. 


\section{APPENDIX A}

\section{ABBREVIATIONS}

\begin{tabular}{|l|l|}
\hline Term & Abbreviation \\
\hline ECM & Extracellular matrix \\
\hline PCL & Polycaprolactone \\
\hline APS & Poly(1,3-diamino-2-hydroxypropane-co-polyol \\
& sebacate) \\
\hline PLA & Poly (L-lactic) acid (PLA) \\
\hline PGA & Polyglycolic acid (PGA) \\
\hline PLGA & Polylactic-co-glycolic acid (PLGA) \\
\hline HFIP & Hexafluoroisopropanol \\
\hline FTIR & Fourier Transform Infrared Spectroscopy \\
\hline DSC & Differential Scanning calorimetry \\
\hline SEM & Scanning electron microscopy \\
\hline CNT & Carbon nanotube \\
\hline
\end{tabular}




\section{BIBLIOGRAPHY}

1. Langer, R. and J. Vacanti, Tissue engineering. Science, 1993. 260(5110): p. 920-926.

2. $\quad$ Sant, S., et al., Tissue Analogs by the Assembly of Engineered Hydrogel Blocks, in Biomimetic Approaches for Biomaterials Development. 2012, Wiley-VCH Verlag GmbH \& Co. KGaA. p. 471-493.

3. Sant, S., et al., Biomimetic gradient hydrogels for tissue engineering. The Canadian Journal of Chemical Engineering, 2010. 88(6): p. 899-911.

4. Di Martino, A., M. Sittinger, and M.V. Risbud, Chitosan: A versatile biopolymer for orthopaedic tissue-engineering. Biomaterials, 2005. 26(30): p. 5983-5990.

5. Madihally, S.V. and H.W.T. Matthew, Porous chitosan scaffolds for tissue engineering. Biomaterials, 1999. 20(12): p. 1133-1142.

6. Sant, S., et al., Effect of biodegradation and de novo matrix synthesis on the mechanical properties of valvular interstitial cell-seeded polyglycerol sebacate-polycaprolactone scaffolds. Acta Biomaterialia, 2013. 9(4): p. 5963-5973.

7. Wang, Y., et al., A tough biodegradable elastomer. Nat Biotech, 2002. 20(6): p. 602-606.

8. Lee, K.-W., D.B. Stolz, and Y. Wang, Substantial expression of mature elastin in arterial constructs. Proceedings of the National Academy of Sciences, 2011. 108(7): p. 27052710.

9. Yoshimoto, H., et al., A biodegradable nanofiber scaffold by electrospinning and its potential for bone tissue engineering. Biomaterials, 2003. 24(12): p. 2077-2082.

10. Yang, F., et al., Fabrication of nano-structured porous PLLA scaffold intended for nerve tissue engineering. Biomaterials, 2004. 25(10): p. 1891-1900.

11. Yang, F., et al., Electrospinning of nano/micro scale poly(l-lactic acid) aligned fibers and their potential in neural tissue engineering. Biomaterials, 2005. 26(15): p. 2603-2610.

12. Sionkowska, A., Current research on the blends of natural and synthetic polymers as new biomaterials: Review. Progress in Polymer Science, 2011. 36(9): p. 1254-1276.

13. Agrawal, C.M. and R.B. Ray, Biodegradable polymeric scaffolds for musculoskeletal tissue engineering. Journal of Biomedical Materials Research, 2001. 55(2): p. 141-150.

14. Amsden, B., Curable, biodegradable elastomers: emerging biomaterials for drug delivery and tissue engineering. Soft Matter, 2007. 3(11): p. 1335-1348.

15. Lendlein, A. and R. Langer, Biodegradable, Elastic Shape-Memory Polymers for Potential Biomedical Applications. Science, 2002. 296(5573): p. 1673-1676.

16. Bettinger, C.J., Biodegradable Elastomers for Tissue Engineering and Cell-Biomaterial Interactions. Macromolecular Bioscience, 2011. 11(4): p. 467-482.

17. Hong, Y., et al., Tailoring the degradation kinetics of poly (ester carbonate urethane) urea thermoplastic elastomers for tissue engineering scaffolds. Biomaterials, 2010. 31(15): p. 4249-4258. 
18. Cohn, D. and A.H. Salomon, Designing biodegradable multiblock PCL/PLA thermoplastic elastomers. Biomaterials, 2005. 26(15): p. 2297-2305.

19. Chen, Q., S. Liang, and G.A. Thouas, Elastomeric biomaterials for tissue engineering. Progress in polymer science, 2013. 38(3): p. 584-671.

20. Fidkowski, C., et al., Endothelialized microvasculature based on a biodegradable elastomer. Tissue engineering, 2005. 11(1-2): p. 302-309.

21. Motlagh, D., et al., Hemocompatibility evaluation of poly (glycerol-sebacate) in vitro for vascular tissue engineering. Biomaterials, 2006. 27(24): p. 4315-4324.

22. Chen, Q.-Z., et al., Characterisation of a soft elastomer poly (glycerol sebacate) designed to match the mechanical properties of myocardial tissue. Biomaterials, 2008. 29(1): p. 47-57.

23. Gupta, S., et al., Adhesive forces significantly affect elastic modulus determination of soft polymeric materials in nanoindentation. Materials Letters, 2007. 61(2): p. 448-451.

24. Ifkovits, J.L., et al., Biodegradable Fibrous Scaffolds with Tunable Properties Formed from Photo-Cross-Linkable Poly(glycerol sebacate). Acs Applied Materials \& Interfaces, 2009. 1(9): p. 1878-1886.

25. Redenti, S., et al., Engineering retinal progenitor cell and scrollable poly (glycerolsebacate) composites for expansion and subretinal transplantation. Biomaterials, 2009. 30(20): p. 3405-3414.

26. Sant, S. and A. Khademhosseini, Fabrication and characterization of tough elastomeric fibrous scaffolds for tissue engineering applications. Conf Proc IEEE Eng Med Biol Soc, 2010. 1: p. 3546-8.

27. Sant, S., et al., Hybrid PGS-PCL microfibrous scaffolds with improved mechanical and biological properties. Journal of tissue engineering and regenerative medicine, 2011. 5(4): p. 283-291.

28. Tong, Z., et al., Controlling the fibroblastic differentiation of mesenchymal stem cells via the combination of fibrous scaffolds and connective tissue growth factor. Tissue Engineering Part A, 2011. 17(21-22): p. 2773-2785.

29. Eslami, M., et al., Fiber-reinforced hydrogel scaffolds for heart valve tissue engineering. Journal of Biomaterials Applications, 2014.

30. Gaharwar, A.K., et al., Anisotropic poly (glycerol sebacate)-poly ( $\epsilon$-caprolactone) electrospun fibers promote endothelial cell guidance. Biofabrication, 2015. 7(1): p. 015001.

31. Wang, J., et al., Biodegradable microfluidic scaffolds for tissue engineering from amino alcohol-based poly(ester amide) elastomers. Organogenesis, 2010. 6(4): p. 212-216.

32. Bettinger, C.J., et al., Amino alcohol-based degradable poly(ester amide) elastomers. Biomaterials, 2008. 29(15): p. 2315-2325.

33. Bettinger, C.J., et al., In vitro and in vivo degradation of poly (1, 3-diamino-2-hydroxypropane-co-polyol sebacate) elastomers. Journal of Biomedical Materials Research Part A, 2009. 91(4): p. 1077-1088.

34. Engelmayr, G.C., et al., Accordion-like honeycombs for tissue engineering of cardiac anisotropy. Nature materials, 2008. 7(12): p. 1003-1010.

35. Yi, F. and D.A. LaVan, Poly (glycerol sebacate) nanofiber scaffolds by core/shell electrospinning. Macromolecular bioscience, 2008. 8(9): p. 803-806. 
36. Stankus, J.J., et al., Hybrid nanofibrous scaffolds from electrospinning of a synthetic biodegradable elastomer and urinary bladder matrix. Journal of Biomaterials Science, Polymer Edition, 2008. 19(5): p. 635-652.

37. Aghdam, R.M., et al., Investigating the effect of PGA on physical and mechanical properties of electrospun PCL/PGA blend nanofibers. Journal of Applied Polymer Science, 2012. 124(1): p. 123-131.

38. Balguid, A., et al., Tailoring fiber diameter in electrospun poly ( $\varepsilon$-caprolactone) scaffolds for optimal cellular infiltration in cardiovascular tissue engineering. Tissue Engineering Part A, 2008. 15(2): p. 437-444.

39. Tan, S.H., et al., Systematic parameter study for ultra-fine fiber fabrication via electrospinning process. Polymer, 2005. 46(16): p. 6128-6134.

40. Megelski, S., et al., Micro-and nanostructured surface morphology on electrospun polymer fibers. Macromolecules, 2002. 35(22): p. 8456-8466.

41. Beachley, V. and X. Wen, Effect of electrospinning parameters on the nanofiber diameter and length. Materials Science and Engineering: C, 2009. 29(3): p. 663-668.

42. Soliman, S., et al., Controlling the porosity of fibrous scaffolds by modulating the fiber diameter and packing density. Journal of Biomedical Materials Research Part A, 2011. 96A(3): p. 566-574.

43. Stankus, J.J., J. Guan, and W.R. Wagner, Fabrication of biodegradable elastomeric scaffolds with sub-micron morphologies. Journal of Biomedical Materials Research Part A, 2004. 70(4): p. 603-614.

44. Wong, S.-C., A. Baji, and S. Leng, Effect of fiber diameter on tensile properties of electrospun poly (E-caprolactone). Polymer, 2008. 49(21): p. 4713-4722.

45. Gao, K., et al., Crystal structures of electrospun PVDF membranes and its separator application for rechargeable lithium metal cells. Materials Science and Engineering: B, 2006. 131(1): p. 100-105.

46. Elzein, T., et al., FTIR study of polycaprolactone chain organization at interfaces. Journal of Colloid and Interface Science, 2004. 273(2): p. 381-387.

47. Elzubair, A., et al., The physical characterization of a thermoplastic polymer for endodontic obturation. Journal of dentistry, 2006. 34(10): p. 784-789.

48. Coleman, M.M. and J. Zarian, Fourier-transform infrared studies of polymer blends. II. Poly( $\epsilon$-caprolactone)-poly(vinyl chloride) system. Journal of Polymer Science: Polymer Physics Edition, 1979. 17(5): p. 837-850.

49. Badrossamay, M.R., et al., Engineering hybrid polymer-protein super-aligned nanofibers via rotary jet spinning. Biomaterials, 2014. 35(10): p. 3188-3197.

50. Salehi, S., et al., Characterization of structural, mechanical and nano-mechanical properties of electrospun PGS/PCL fibers. RSC Advances, 2014. 4(33): p. 16951-16957.

51. Kim, H.K. and T.G. Park, Comparative study on sustained release of human growth hormone from semi-crystalline poly(l-lactic acid) and amorphous poly(d,l-lactic-coglycolic acid) microspheres: morphological effect on protein release. Journal of Controlled Release, 2004. 98(1): p. 115-125.

52. You, Y., et al., In vitro degradation behavior of electrospun polyglycolide, polylactide, and poly (lactide-co-glycolide). Journal of Applied Polymer Science, 2005. 95(2): p. 193200.

53. Spyros, A., et al., H NMR Imaging Study of Enzymatic Degradation in Poly(3hydroxybutyrate) and Poly(3-hydroxybutyrate-co-3-hydroxyvalerate). Evidence for 
Preferential Degradation of the Amorphous Phase by PHB Depolymerase B from Pseudomonas lemoignei. Macromolecules, 1997. 30(26): p. 8218-8225.

54. Gaharwar, A.K., et al., Physically Crosslinked Nanocomposites from Silicate-Crosslinked PEO: Mechanical Properties and Osteogenic Differentiation of Human Mesenchymal Stem Cells. Macromolecular Bioscience, 2012. 12(6): p. 779-793.

55. Kakade, M.V., et al., Electric field induced orientation of polymer chains in macroscopically aligned electrospun polymer nanofibers. Journal of the American Chemical Society, 2007. 129(10): p. 2777-2782.

56. Ciofani, G., et al., Investigation of interactions between poly-L-lysine-coated boron nitride nanotubes and C2C12 cells: up-take, cytocompatibility, and differentiation. International journal of nanomedicine, 2010. 5: p. 285.

57. Sirivisoot, S. and B.S. Harrison, Skeletal myotube formation enhanced by electrospun polyurethane carbon nanotube scaffolds. International journal of nanomedicine, 2011. 6: p. 2483.

58. Ku, S.H. and C.B. Park, Myoblast differentiation on graphene oxide. Biomaterials, 2013. 34(8): p. 2017-2023.

59. Jun, I., S. Jeong, and H. Shin, The stimulation of myoblast differentiation by electrically conductive sub-micron fibers. Biomaterials, 2009. 30(11): p. 2038-2047. 